\title{
Global Structure of Ionospheric TEC Anomalies Driven \\ by Geomagnetic Storms
}

\author{
D. Pancheva*, P. Mukhtarov, and B. Andonov \\ National Institute of Geophysics, Geodesy and Geography, Bulgarian Academy of Sciences, \\ Sofia, Bulgaria
}

\begin{abstract}
This study examines the structure and variability of the ionospheric TEC anomalies driven by geomagnetic storms. For this purpose the CODE global ionospheric TEC data from four geomagnetically disturbed periods (29 October-1 November 2003, 7-10 November 2004, 14-15 December 2006, and 5-6 August 2011) have been considered. By applying the tidal analysis to the geomagnetically forced TEC anomalies we made an attempt to identify the tidal or stationary planetary wave (SPW) signatures that may contribute to the generation of these anomalies. It has been found that three types of positive anomalies with different origin and different latitudinal appearance are observed. These are: (i) anomalies located near latitudes of $\pm 40^{\circ}$ and related to the enhancement and poleward moving of the equatorial ionization anomaly (EIA) crests; (ii) anomalies located near latitudes of $\pm 60^{\circ}$ and seen predominantly in the night-side ionosphere, and (iii) very high latitude anomalies having mainly zonally symmetric structure and related to the auroral heating and thermospheric expansion. The decomposition analysis revealed that these anomalies can be reconstructed as a result of superposition of the following components: zonal mean (ZM), diurnal migrating (DW1), zonally symmetric diurnal (D0), and stationary planetary wave 1 (SPW1).
\end{abstract}

Key words: geomagnetic storm, geomagnetically forced TEC anomalies, tidal analysis

* Corresponding author: Dora Pancheva, e-mail: dpancheva@geophys.bas.bg 


\section{Introduction}

During the geomagnetic disturbances, which are excited through the interaction between coronal mass ejections (CMEs) and the Earth's magnetic field, the energy inputs lead to substantial effects in the upper atmosphere and the ionosphere. One of these effects is the significant perturbation of the "quiet-time" ionosphere due to large variability in the ionospheric density distribution, total electron content (TEC), and the ionospheric current system. The rapid and global response of the ionosphere to these strong geomagnetic disturbances is well studied [Mendillo et al., 1970, 1992; Prölss, 1980, 1991, 1993, 1995, 2008; Rishbeth, 1991, 1998; Field and Rishbeth, 1997; FullerRowell et al., 1994, 1996, 2000; Muhtarov and Kutiev, 1998; Buonsanto, 1999; Kutiev and Muhtarov, 2001, 2003; Jakowski et el., 2005; Mendillo, 2006; Trichtchenko et al., 2007; Stankov et al., 2010; Balan et al., 2010, 2011].

During intense geomagnetic storms drastic modifications to dynamics, electrodynamics and chemistry of the Earth's atmosphere-ionosphere system take place on a global scale. Three dominant causes of storm effects have been suggested to explain the positive and negative phases of ionospheric storms: thermospheric composition changes, neutral wind perturbations and the appearance of electric fields of magnetospheric origin [Mendillo, 2006]. Satellite neutral mass spectrometer measurements showed that the negative phase of ionospheric storms is mainly due to the composition changes [Rishbeth, 1991; Prölss, 1980, 1995, 2011], i.e. the thermosphere becomes richer in molecular nitrogen and poorer in atomic oxygen. The causes of the positive ionospheric storms have also been clarified recently finding that these are the combined effects of disturbed thermospheric wind and electric fields [Tanaka, 1979, 1981, Reddy et al., 1990; Werner et al., 1999; Kelley et al., 2004; Balan et al., 2010]. Kelley et al. [2004] suggested that, in the presence of daytime ionization an eastward prompt penetration electric field (PPEF) can strengthen the equatorial plasma fountain to a super plasma fountain, which, in turn, can lead to positive ionospheric storms at midlatitudes. However, modeling studies later showed that a daytime eastward PPEF on its own is unlikely to produce positive ionospheric storms; an equatorward neutral wind is required also to produce positive ionospheric storms [Werner et al., 1999; Lin et al., 2005; Lu et al., 2008; Balan et al., 2009].

Disturbed electric fields are the major source of ionospheric modifications over equatorial and low latitudes. During the development of the storm large polar cap dawn-dusk electric field promptly penetrates to equatorial latitudes [Kelley et al., 1979; Fejer and Scherliess, 1998; Kikuchi et al., 1996]. The PPEF have eastward polarity during the day- and westward polarity during the nightside of the equatorial ionosphere. The PPEF of eastward polarity can cause large uplift of the ionosphere resulting in large increase of the TEC. During such TEC storms the equatorial ionization anomaly (EIA) can expand poleward with the ionization crests displaced to midlatitudes [Mannисci et al., 2005]. It is also well known that the global thermospheric disturbances originating from the auroral heating produce long duration electric fields, known as disturbance dynamo electric fields (DDEF) [Blanc and Richmond, 1980] that dominate the low latitudes with a delay of $4-5 \mathrm{~h}$ from the first incidence of the PPEF following the storm onset. These electric fields could last several hours up to one day and have polarity that is nearly opposite to that of the PPEF [Richmond et al., 2003]. Therefore, the occurrence of strong daytime eastward and westward electric fields at equatorial latitudes during the main phase of geomagnetic storms seems to be due to PPEF and DDEF, respectively [Batista et al., 1991; Abdu et al., 2006; Fejer et al., 2007].

The positive ionospheric storms observed at subauroral latitudes [Mendillo and Klobuchar, 1975] have been interpreted in terms of the equatorward expansion of the convection electric fields, with no plasma transfer from low latitudes [Foster, 1993; Foster et al., 2002; Foster and Rideout, 2007]. Heelis et al. [2009] suggested that the convection electric field at higher latitudes can push plasma to high altitudes where the recombination is much slower, i.e. plasma accumulation occurs. The geomagnetically driven equatorward winds can strengthen the positive storms at subauroral latitudes also [Balan et al., 2011]. 
It has been already mentioned that the geomagnetic storms dramatically change the ionosphere which affects all branches of telecommunication and navigation and can have significant, adverse effects on ground- and space-based technological systems. Some important terrestrial consequences include possible damage to satellites caused by high energy particles, disrupting UHF satellite communications or detection and tracking of aircrafts, missiles and other targets, increased risk of radiation exposure by humans in space and in high-altitude aircraft, changes in atmospheric drag on satellites. The negative ionospheric storms in which the electron density $N_{e}$, peak electron density $N_{\max }$ and TEC decrease much below their normal levels may cause serious problems in groundbased HF radio communications. The negative storms therefore received much attention first when the communications were developed mainly on the HF radio waves. The positive ionospheric storms in which $N_{e}, N_{\max }$ and TEC increase much above their normal levels can cause serious problems (such as time delay, range error and scintillations) in satellite communication and navigation. Because the GPS signals are used by wide range of applications, any geomagnetic storm event which makes GPS signal unreliable could have significant impact on the society. Hence the monitoring of ionosphere, particularly during the geomagnetic storms, and modeling and forecasting the evolution of the ionospheric variability are among the important tasks of the ionosphere studies.

Traditionally atmospheric tidal analysis is applied mainly to the dynamics of the neutral middle atmosphere however recently it has been successfully applied to ionospheric parameters as well [Pancheva and Mukhtarov, 2010; 2012]. Using this method, ionospheric fields are decomposed in terms of coherent, global-scale oscillations that are sinusoidal in time and longitude. Such tidal analysis of the ionosphere has been utilized primarily for understanding atmosphere -ionosphere coupling through upward propagating tides excited in the lower and middle atmosphere [Pancheva and Mukhtarov, 2010], although in-situ generated ionospheric phenomena have been studied as well in the context of their constituent tidal components [Jones et al., 2013]. Recently, the tidal concept with including migrating and non-migrating diurnal oscillations and zonal waves with different wave numbers has been successfully used in constructing a mean empirical TEC model [Mukhtarov et al., 2013a] based on the global ionospheric TEC maps produced by the Center for Orbit Determination in Europe (CODE). Due to this the model is able to reproduce the well-known ionospheric structures such as the Weddell Sea Anomaly (WSA) and some longitudinal wave-like structures as ionospheric wave 3 and wave 4 variations. Recently Chang et al. [2015] have applied tidal decomposition to FORMOSAT-3/COSMIC TEC data to quantify the components dominating local time and spatial variation in the WSA region and found that the features of the WSA can be reconstructed as the result of superposition between the dominant zonally symmetric diurnal (D0), eastward wavenumber 1 (DE1), westward wavenumber 2 (DW2), and stationary planetary wave 1 (SPW1) components in TEC.

The basic goal of the present paper is to make an attempt to clarify the main components dominating local/universal time (LT/UT) and spatial variations in the ionospheric anomalies driven by geomagnetic storms. This will be done by applying tidal decomposition to the geomagnetically forced TEC anomalies, defined from the CODE TEC data, through studying of 4 (four) geomagnetic storms. First the October 29-30, 2003 (Halloween) geomagnetic storms were investigated in detail and then the same approach was applied to the following storms: 7-10 November 2004, 14-15 December 2006 and 5-6 August 2011.

\section{TEC data and methodology}

The vertical TEC maps generated by the Center for Orbit Determination of Europe (CODE) at Astronomical and Physical Institutes of the University of Bern, Switzerland (http://cmslive3.unibe.ch/unibe/philnat/aiub/content/e15/ e59/e126/e440/e447/index_eng.html) are used in this study. The TEC at CODE is modeled with a spherical harmonic expansion up to degree of order 15 referring to a solar-geomagnetic reference frame [Schaer, 1999] and the TEC maps are 
based on GPS data from more than 200 stations around the globe. The global TEC data have a time resolution of $2 \mathrm{~h}$ and a grid spacing of $5^{\circ} \times 2.5^{\circ}$ in longitude and latitude, respectively with errors of several TEC Units (TECU, 1 TECU $=10^{16} \mathrm{el} / \mathrm{m}^{2}$ ) [Hernández-Pajares et al., 2009]. The time resolution of $1 \mathrm{~h}$ is used in this study and the hourly data are obtained by interpolation of the 2hourly original data. More details about the CODE TEC data can be found in Mukhtarov et al., [2013b].

The geomagnetic anomalies are described by the relative deviation of TEC from its sliding median and are denoted as rTEC. Then $\mathrm{rTEC}=\left(\mathrm{TEC}_{\mathrm{obs}}-\mathrm{TEC}_{\mathrm{med}}\right) / \mathrm{TEC}_{\mathrm{med}}$ where the terms $\mathrm{TEC}_{\mathrm{obs}}$ and $\mathrm{TEC}_{\text {med }}$ represent observed and median TEC values respectively at a given hour. It is important the geomagnetic anomalies presented by rTECs to be able to detect and correctly describe those CODE rTEC anomalies which are generated by geomagnetic disturbances. Such anomalies have usually time scales of a few days up to a week. Due to this a smaller than a month median has to be used. The preliminary examinations revealed that using a 15-day median provides the best opportunity for studying the main features of the TEC anomalies driven by geomagnetic storms. The 15-day window is used also because of the following two reasons: (i) the contribution of the $\sim 27$-day rTEC oscillation due to the solar rotation variability of the EUV radiation is significantly weaken, and (ii) such window has an insignificant effect on the 9- and 13.5-day recurrent geomagnetic activity oscillations which are particularly strong during the declining phase of the solar activity [Mukhtarov and Pancheva, 2012].

It is worth underlying that by using rTEC the regular diurnal, seasonal and solar changes as well as the background (stable) zonal structures (i.e. regularly observed zonal structures as WSA or ionospheric wave 4, etc.) are removed from the TEC variability. This means that if the tidal analysis is applied to the geomagnetically forced anomalies rTEC the obtained enhanced tidal or zonal wave signatures will be entirely driven by the geomagnetic storms. Therefore, the cornerstone of this study is that for the first time the geomagnetically forced anomalies are suggested to be understood and quantified by using the concept of tides/zonal waves in the ionosphere. By examining of several geomagnetic storms we will be able to clarify which wave components describe the main structure and evolution of the geomagnetically forced TEC anomalies.

It has been already mentioned that the traditional tidal analysis was for the first time successfully applied to ionospheric parameters by Pancheva and Mukhtarov [2010] where the decomposition procedure is described. More details about the application of the tidal analysis to ionospheric measurements can be found also in the review paper [Pancheva and Mukhtarov, 2012]. Here we will clarify only that having in mind the time and spatial scales of TEC anomalies observed during geomagnetic storms the following components have to be included in the decomposition: (i) zonal mean; (ii) tidal oscillations with periods 24, 12 and 8 hours and with zonal wave numbers up to 3, and (iii) four zonal waves. For each altitude and latitude all these tidal/zonal wave components are separated simultaneously from the rTEC data by using 24-hour window that moves through the time series with steps of 1 hour in order to obtain the hourly values of the wave characteristics. The wave components are extracted from the data by using a linear two-dimensional (time-longitude) least squares fitting technique described by Pancheva et al. [2009]. In this way the global spatial distribution and temporal variability of each wave component during the geomagnetically disturbed periods is obtained and later investigated in order some relationship with the stages of the storm to be found.

\section{October 29-30, 2003 Halloween storms}

The duration and strength of the geomagnetic storms are described by the time series of the equatorial $\mathrm{D}_{\mathrm{st}}$-index and the global 3-hourly $K_{p}$-index. The data are downloaded from the Space Physics Interactive Data Resource (SPIDR), Boulder, Colorado for the considered period of time. The National Oceanic and Atmospheric Administration (NOAA) Hemispheric Power Index (PI) 
will be used only for the October 29-30, 2003 geomagnetic storms because they will be studied in detail.

During the period 29-30 October, 2003 three geomagnetic storms were observed as the last two of them were superstorms. The first geomagnetic storm is associated with an abrupt decrease of the equatorial $\mathrm{D}_{\text {st }}$-index (Figure 1a, upper left plot), with a peak of $\sim 180 \mathrm{nT}$ at $\sim 0900$ UT on 29 October accompanying also with a sudden jump of the $\mathrm{K}_{\mathrm{p}}$-index up to 9 (Figure 1a, upper right plot). The next storm is with a $\mathrm{D}_{\text {st }}$-index of $\sim 363 \mathrm{nT}$ at $2330 \mathrm{UT}$ on 29 October and $\mathrm{K}_{\mathrm{p}}$-index close to 9 . The last storm is the most intense, with a peak $\mathrm{D}_{\mathrm{st}}$-index of $\sim 400 \mathrm{nT}$ at $2315 \mathrm{UT}$ on 30 October and $\mathrm{K}_{\mathrm{p}^{-}}$ index again 9. After the third storm main phase, according to the $\mathrm{D}_{\mathrm{st}}$-index, the October geomagnetic event started to recover on 31 October. The $K_{p}$-index decreases to 3 on 01 November at 12 UT but the geomagnetic storm is still in its recovery phase and far from quiet with Dst around $-40 \mathrm{nT}$ at that time. The auroral heating is described by the NOAA Hemispheric PI for Northern Hemisphere $(\mathrm{NH})$ (blue color) and Southern Hemisphere (SH) (red color) shown in right plot of Figure 1a. This index presents the estimated power in gigawatts deposited in the polar regions by energetic particles during transits over the poles by the NOAA Polar-orbiting Operational Environmental Satellite (POES) http://www.swpc.noaa.gov/.

Figure $1 \mathrm{~b}$ shows the relative CODE TEC maps in geographic coordinates for the given universal times (UT) noted at the upper side of each plot; they are related to the main phases of the above described storms. The modip latitude is marked by white line while the terminator is shown by grey line. The upper plot shows the rTEC map on October 29 at 09 UT when $K_{p}$-index suddenly jumps up to 9 and during the main phase of the first storm defined by the $\mathrm{D}_{\text {st }}$-index. There are positive anomalies during evening, night and early morning hours above American and Pacific regions at latitudes between $40^{\circ}-70^{\circ} \mathrm{N}$. A careful inspection of the anomalies particularly at longitudes near $150^{\circ}-180^{\circ} \mathrm{W}$ reveals that there are two latitudinally narrow stripes of anomalies situated northward and southward of $60^{\circ} \mathrm{N}$ that most probably have different origins. The response of the tropical region and the SH is mainly negative. The observed hemispheric asymmetry could be partly related to asymmetry in the NOAA Hemispheric PI which is significantly stronger for the NH than that for the SH (bottom plot in Figure 1a).

The second plot of Figure 1b displays the rTEC map on October 30 at 00 UT during the main phase of the second storm (first superstorm). There are two types of positive anomalies: those observed near latitudes of $\pm 60^{\circ}$ and predominantly occurred in the night-side ionosphere and disturbances most probably related to the enhanced and poleward moved EIA crests forced by the combined action of the eastward PPEF [Kelley et al., 2004] and disturbed equatorward wind [Balan et al., 2009]. The latter are seen during the afternoon and evening hours. The hemispheric asymmetric response is evident again for both types of positive anomalies. A positive anomaly can be seen also in the $\mathrm{SH}$ around latitude of $\sim 60^{\circ} \mathrm{S}$ and longitude of $\sim 60^{\circ} \mathrm{E}$; this feature will be seen again later during the maximum of the third geomagnetic storm (bottom plot). The negative response is observed above the equator and at the day-side subauroral regions at both hemispheres.

The third plot in Figure $1 \mathrm{~b}$ presents the rTEC map for 30 October at 12 UT, during the recovery phase of the second storm when the Kp-index decreases to $\sim 5$. Mainly negative anomalies are seen which are connected with composition changes [Rishbeth, 1991; Prölss, 1980, 1995, 2011].

The bottom plot in Figure 1b shows the rTEC map for 30 October at 23 UT which is during the main phase of the third geomagnetic storm (second superstorm). Overall this TEC response is very similar to that during the main phase of the second storm, 30 October at $00 \mathrm{UT}$, and all features of the TEC response mentioned above are valid here as well. However the amplitudes of the positive anomalies in the night-side ionosphere (near $\pm 60^{\circ}$ ) are larger while those related to the EIA are weaker than the respective anomalies for the previous storm. The stronger positive response particularly for the NH night-side ionosphere again could be partly caused by the larger NOAA Hemispheric PI for the third storm than for the second one (bottom plot in Figure 1a). 
From the above rTEC maps we have distinguished repeatable features of the TEC anomalies driven by the geomagnetic storms. They can be summarized as: (i) positive anomalies related to the EIA (near $\pm 40^{\circ}$ ) during the main phases of the two superstorms; they are seen in the afternoon and evening hours and characterized the poleward moving of the enhanced equatorial crests particularly strong in the $\mathrm{NH}$ (second and bottom plots); (ii) positive anomalies of the night-side subauroral ionosphere (near $60^{\circ}$ ) better seen during the main phase of the second superstorm (second and bottom plots), and (iii) an almost absence of the EIA, i.e. negative anomalies, during the recovery phase of the first superstorm (third plot).

Figure 2 shows the latitudinal structure of the rTEC at some fixed longitudes during 29 October 01 November 2003. This is done to separate the longitudinal dependence of the geomagnetically forced TEC anomalies and to direct attention to their latitudinal, LT and UT dependence. Four longitudinal bands are presented in Figure 2 as the data are averaged over $10^{\circ}$ around the longitudes: $180^{\circ} \mathrm{W}$ (upper plot); $90^{\circ} \mathrm{W}$ (second plot); $00^{\circ} \mathrm{E}$ (third plot) and $90^{\circ} \mathrm{E}$ (bottom plot). The rTEC results at all plots reveal positive anomalies at latitudes around $\pm 40^{\circ}$ which are related to the main phases of the storms however at different longitudes the hemispheric asymmetry and the time of their peaks are different. For example, at longitude of $180^{\circ} \mathrm{W}$ the $\mathrm{NH}$ anomalies are significantly larger than those in the $\mathrm{SH}$ while at longitude of $90^{\circ} \mathrm{E}$ the situation is the opposite. While the $\mathrm{NH}$ anomalies have the largest amplitudes after the maxima of the superstorms those in the $\mathrm{SH}$ maximize during the maxima of the superstorms. All plots show also positive anomalies around latitudes of $\pm 60^{\circ}$ which are definitely stronger in the $\mathrm{NH}$; at some longitudes they almost absent in the SH. They are well evident at longitude around $00^{\circ} \mathrm{E}$, i.e. at the Greenwich meridian; it is worth noting that here the plots show actually the LT. This means that the geomagnetic storms generate besides nonmigrating tidal anomalies also migrating ones. The forcing of the migrating diurnal and semidiurnal waves by geomagnetic storms was reported first by Muhtarov and Kutiev [1998] on the basis of the analysis of $f_{o} F 2$ from 24 ionospheric stations situated at middle latitudes $\left(35^{\circ}-55^{\circ}\right)$. Further all plots display positive anomalies around latitudes of $80^{\circ}-90^{\circ} \mathrm{S}$; only the largest of them are related to the main phases of the geomagnetic storms. These anomalies can be distinguished in Figure $1 \mathrm{~b}$ as well as a weak narrow latitudinal stripe of rTEC at very high latitudes of the SH connected with the two superstorms. The negative anomalies are seen predominantly during the recovery phases of the superstorms; latitudinally, they are not so well defined as the positive ones. They are present at all longitudes and are stronger during the night-side ionosphere.

The analysis performed on the geomagnetically forced TEC anomalies so far indicates that particularly the positive anomalies clearly demonstrate repeatable spatial distribution depending both on LT and UT. It is important to remind that by using rTEC for describing the TEC anomalies the regular temporal and spatial variations are removed in advance. This means that if the rTEC data are decomposed into tidal and zonal wave components and some of them have large amplitudes then these components have to be forced by the geomagnetic storms.

The next step is to apply the tidal analysis to the rTEC. As it has been mentioned before the decomposition includes all main tidal components with periods 24, 12 and 8 hours and zonal wave numbers up to 3 as well as zonal waves, known as stationary planetary waves (SPWs), with zonal wave numbers up to 4 . We remind that the phases of the tidal waves are defined as the time (in UT) of the wave maxima at zero longitude and are presented in degrees (or longitude of maxima at 00 UT), while the phases of the SPWs are defined as the longitude of the wave maximum. Due to the relationship between UT, LT and longitude it is worth clarifying that the phases of the migrating tidal waves are actually given in LT. We note that besides the tidal and zonal waves the decomposition defines also the zonal mean (ZM) component which is actually zonal and time mean for the used 24-hour window. This component can describe longer than 24 hours zonally symmetric waves which may be forced by geomagnetic storms. The variability of ZM with periods of 24, 12, and 8 hours is presented by zonally symmetric (with zonal wave number zero) tidal oscillations.

The first step in assessing which wave components have dominant effect in shaping the positive TEC anomalies is made by calculating the root mean squares (RMS) of each component. The RMS 
results for all components included in the decomposition are shown in Figure 3 as a chart; each component is denoted at the upper part of its RMS (for example, 24s-3 means a diurnal tide with zonal wave number -3$)$. Both RMS of the data (0.594) and of the full decomposition (0.553) for the same period of time are shown also in the upper part of the chart. The two RMS values are very close; this means that the full decomposition describes almost entirely the existing TEC anomalies; the small difference between both RMS values belongs to the noise. The chart shows that the largest contribution to the TEC anomalies belongs to the ZM component which describes anomalies not depending on the longitude and LT. The next dominant components are diurnal migrating and zonally symmetric diurnal components with very similar RMS values, the zonal wave 1 denoted as SPW1 (stationary planetary wave 1 in the context of tidal analysis) and the zonally symmetric semidiurnal and terdiurnal components. These are the dominant components that could describe the structure and evolution of the geomagnetically forced TEC anomalies during the considered disturbed conditions.

Figure $4 \mathrm{a}$ presents the latitude-UT cross-section of the ZM calculated from the rTEC. Two narrow but significantly enhanced latitudinal stripes of the ZM components can be distinguished: the highand middle latitude components. The NH high latitude ZM outlines well the subauroral area (near $60^{\circ} \mathrm{N}$ ) where the positive anomalies are generated mainly by the equatorward expansion of the convection electric fields and particle precipitations, with no plasma transfer from low latitudes [Foster, 1993; Foster et al., 2002; Foster and Rideout, 2007]. This component is related to the auroral heating described by the NH PI shown in Figure 1a (bottom plot) and the two enhancements are in accordance with the two maxima of the NH PI. The SH high latitude $\mathrm{ZM}$ near $60^{\circ} \mathrm{S}$ is significantly weaker than the $\mathrm{NH}$ one; however the very high latitude $\mathrm{ZM}$ situated at $\sim 80^{\circ} \mathrm{S}$ is well outlined. The midlatitude ZMs are located around $\pm 40^{\circ}$ and their enhancement is partly related to the main phases of the storms; the NH ZM is larger than the SH one.

Figure $4 \mathrm{~b}$ displays the latitude-UT cross-section of the amplitude of the migrating diurnal oscillation (DW1) extracted from the rTEC. This component has a second important contribution to the formation of the anomalies driven by the considered storms. The spatial and temporal distribution of the DW1 is similar to that of the ZM except the absence of the DW1 enhancement at very high latitudes in the SH. The high-latitude DW1 (near $\pm 60^{\circ}$ ) amplifies near the main phases of both superstorms. The midlatitude DW1 (near $\pm 40^{\circ}$ ) enhancements are due to the PPEF of eastward polarity during the day causing large uplift of the ionosphere that leads to large increase of the TEC and poleward moving of the ionization crests [Mannucci et al., 2005]. The main amplification is related primarily to the main phase of the first superstorm and it is seen also in Figure $1 \mathrm{~b}$ (second plot). Figure $4 \mathrm{c}$ shows the DW1 phase (in LT) at latitudes where the DW1 wave has large amplitudes: at $\pm 40^{\circ}$ (left plot) and $\pm 60^{\circ}$ (right plot). The midlatitudes DW1 phases at both hemispheres demonstrate some trend starting from afternoon hours, about 15-16 LT during the main phase of the first storm (09 UT on October 29), and moving to evening hours, 20 LT for the NH and $\sim 22 \mathrm{LT}$ for the $\mathrm{SH}$ at the mid-day on October 31, i.e. during the recovery phase of the second superstorm. This is important evidence that the DW1 tidal oscillation at middle latitudes is a dominant component defining the structure of the TEC anomalies related to the EIA response to the geomagnetic storms [Mannucci et al., 2005]. The DW1 phases at high latitudes (around $\pm 60^{\circ}$ ) are around midnight indicating that this DW1 wave amplifies during night-time and is not related to plasma transfer from low latitudes; its origin most probably is connected with the equatorward expansion of the convection electric fields [Foster, 1993; Foster et al., 2002; Foster and Rideout, 2007].

Figure 5a shows the latitude-UT cross-section of the amplitudes of the zonally symmetric diurnal (D0) (left plot) and semidiurnal (S0) (right plot) tidal components calculated from the rTEC for the period of time 29 October - 01 November 2003. The terdiurnal (T0) tidal wave has very similar to S0 spatial structure but its contribution to the shape of the high-latitude TEC anomalies is significantly smaller than those of D0 and S0 components (see Figure 3) and due to this is not considered here. While the DW1 and D0 waves have very close amplitudes and similar RMS values 
(Figure 3) those of the SW2 and S0 are very different; the amplitude of the nonmigrating S0 wave is more than two times larger than that of the migrating SW2 (not shown result for SW2 but this is seen in their RMS values as well). The spatial distribution of the D0 is very similar to that of the $\mathrm{ZM}$, high-latitude enhancement near $\pm 60^{\circ}$ and some midlatitude one near $\pm 40^{\circ}$. The D0 shows additional very high-latitudinal enhancements near $\pm 80^{\circ}$. This last D0 enhancement is most probably related to the significant expansion of the thermosphere that leads to increase in the neutral gas scale height. Investigating the recurrent geomagnetic storms effect on the ionosphere Mukhtarov and Pancheva [2012] found that the periodical thermospheric expansion leads to a decrease of the top vertical gradient of the electron density profile. This is due to the prevailing role of the dynamics and diffusion processes in shaping the top side F-region during the winter. In this case the two superstorms force the ionosphere with a period of about 24 hours and the D0 is its response. The spatial distribution of the nonmigrating S0 component shows predominantly high (near $\pm 60^{\circ}$ ) and very high (near $\pm 80^{\circ}$ ) enhancements. The zonally symmetric waves near $\pm 60^{\circ}$ are stronger in the $\mathrm{NH}$ while those near $\pm 80^{\circ}$ are stronger in the $\mathrm{SH}$. Figure $5 \mathrm{~b}$ shows the phases (in UT) of the considered D0 (left column of plots) and S0 (right column of plots) for latitudes $\pm 60^{\circ}$ (upper row of plots) and $\pm 80^{\circ}$ (bottom row of plots). Again the phases for the $\mathrm{NH}$ are in blue color while those for the SH are in red color. The phases at both latitudes and for both nonmigrating tidal components clearly show that they maximize near 23-00 UT; the phase behavior is also evidence that these tidal components are forced by the considered geomagnetic superstorms whit main phases around $00 \mathrm{UT}$.

The longitudinal dependence of the geomagnetically forced TEC anomalies is described predominantly by the zonal wave 1 (or SPW1). According to the RMS values of the all decomposition components shown in Figure 3 the nonmigrating tidal waves DW2, DE1 and SW1 also contribute to the longitudinal structure of the TEC anomalies but they have some secondary effect. Figure $6 a$ displays the latitude-UT cross-section of the SPW1 amplitude during the considered time interval. The spatial distribution of the SPW1 is very similar to that of the DW1; high-latitude enhancement (near $\pm 60^{\circ}$ ) and midlatitude one (near $\pm 40^{\circ}$ ). While the high-latitude enhancements are stronger in the $\mathrm{NH}$ than those in the $\mathrm{SH}$ (like DW1) the midlatitude enhancements are very similar. Figure $6 \mathrm{~b}$ shows the SPW1 phases (in degrees) for latitudes where there are significant amplitude enhancements. These latitudes are: $\pm 40^{\circ}$ (left plot) and $\pm 60^{\circ}$ (right plot). The midlatitude SPW1 phases at both hemispheres show similar and very interesting behavior during the considered four days. They are located around $60-100^{\circ} \mathrm{E}$ at the beginning of October 29 and gradually moves westward making almost a complete longitudinal cycle at the end of November 01. During the disturbed days however (from mid-day on 29 to October 31) the SPW1 phases are in the Western Hemisphere where the large positive anomalies have been observed (Figure 1b). The high latitude SPW1 phases has different behavior; during the main phase of the first storm $(\sim 09 \mathrm{UT}$ on October 29$)$ they have phases $\sim 150^{\circ} \mathrm{W}$ in the $\mathrm{NH}$ and $\sim 120^{\circ} \mathrm{E}$ in the SH, i.e. at longitudes close to the geomagnetic poles. This is strong evidence indicating that the auroral heating is the origin of the first enhancement of the SPW1. It is worth remaining that by using SABER/TIMED temperature data Mukhtarov et al. [2010] presented strong evidence indicating that auroral heating is a main origin of the lower thermospheric SPW1. The main phases of the next two superstorms are near midnight at $0^{\circ}$ longitude and due to this the SPW 1 phases move to longitudes $\sim 0-60^{\circ} \mathrm{E}$ where they remain almost stable during the main phases of the two superstorms. This means that the SPW1 component contributes to the formation of the night-time enhancements of the positive anomalies near $\pm 60^{\circ}$ (second and bottom plot in Figure $1 \mathrm{~b}$ ).

It has been already mentioned that the negative anomalies are not latitudinally well defined however it does not mean that they cannot be described by the applied tidal analysis. The ZM (Figure 4a) describes this part of the negative anomalies that does not depend on the longitude and LT. The tidal components, as DW1 (Figure 4b,c), D0 and S0 (Figure 5), contribute to the time dependent part of the negative anomalies and due to this they are seen predominantly during the recovery 
phases of the superstorms. The SPW1 component (Figure 6) defines the dependence of the negative anomalies on the longitude.

The presented in this part results clarified which wave components included in the decomposition have the largest contribution to the formation of the positive geomagnetically forced TEC anomalies during the October 29-30, 2003 Halloween geomagnetic storms.

\section{Results for other geomagnetic storms}

Tidal analysis presented in the Part 3 will be applied to the TEC anomalies observed in the following disturbed period of times: (i) 07-10 November 2004; (ii) 13-16 December 2006, and (iii) 04-07 August 2011. Their geomagnetic conditions are described by $\mathrm{D}_{\mathrm{st}^{-}}$and $\mathrm{K}_{\mathrm{p}}$-indexes and the results are shown in the upper and middle rows of plots in Figure 7 respectively. For each disturbed interval the rTECs are calculated and later the decomposition analysis with the same wave components as those included in the October 2003 storms is applied. The first step in estimating the contribution of each wave component is done by calculating the RMS. The RMS values for each decomposition component and for the considered three disturbed intervals are shown in the bottom row of plots in Figure 7. Again both RMS of the data and of the full decomposition are shown in the upper part of each chart. For all disturbed intervals the two RMS values are very close indicating again that the included in the decomposition waves describe almost entirely the geomagnetically forced TEC anomalies.

The ZM component has again the largest contribution to the geomagnetically forced anomalies for all considered storms. The November 2004 disturbed interval is similar to October 2003 because of the presence of two successive storms: 7-8 and 9-10 November. Probably due to this the same wave components as those for October 2003 have large contribution to the TEC anomalies. These wave components according to their contributions are: migrating DW1, nonmigrating D0, wave 1 (SPW1), and nonmigrating S0 and T0 waves. For the second disturbed interval, 13-16 December 2006, the following components have large contribution: migrating DW1, nonmigrating D0, wave 1 (SPW1), migrating SW2 and nonmigrating S0 and T0. For the third disturbed interval, 04-07 August 2011, the components with large contribution are: nonmigrating D0 and S0, wave 1 (SPW1), migrating DW1 and nonmigrating T0. The above RMS results reveal that the largest contribution to the TEC anomalies has almost the same wave components for all geomagnetic storms considered in this study.

In general the RMS values of semidiurnal and terdiurnal tidal components are significantly smaller than those of the diurnal and SPW1 components for the considered geomagnetic storms. Due to this only the spatial and temporal distribution of the components ZM, DW1, D0 and SPW1 will be considered.

Figure 8 shows the latitude-UT cross sections of ZM (left column of plots) and amplitudes of DW1 (right column of plots) component calculated from the CODE rTEC for the following disturbed periods: 07-10 November 2004 (upper row of plots), 13-16 December 2006 (middle row of plots) and 04-07 August 2011 (bottom row of plots). The spatial distributions of both decomposition components for the considered disturbed three intervals are very similar to those of October 2003; there are latitudinally limited enhancements related to the main phases of the storms and located near latitudes of $\pm 40^{\circ}$ and $\pm 60^{\circ}$. Similarly to the October 2003 case, the enhanced ZM and particularly the DW1 tidal oscillations around latitudes of $\pm 40^{\circ}$ are due to the PPEF of eastward polarity during the day causing large uplift of the ionosphere that leads to large increase of the TEC and poleward moving of the ionization crests [Mannucci et al., 2005]. This result is supported by the DW1 phases at both hemispheres which show that the DW1 waves have the largest amplitudes mainly in the afternoon and early evening hours (results not shown), i.e. as in the case for October 2003 storms. The subauroral enhancements around $\pm 60^{\circ}$ are caused by the equatorward expansion of the convection electric fields and particle precipitations, with no plasma transfer from low 
latitudes [Foster, 1993; Foster et al., 2002; Foster and Rideout, 2007]. They are night-time events because the DW1 phases at latitudes of $\pm 60^{\circ}$ are around midnight (also not shown result as it is similar to that of October 2003 case).

The hemispheric asymmetry is seen in the considered storms. It is particularly strong for the last two storms which occur in boreal winter (13-16 December 2006) and summer (04-07 August 2011). For these storms some of the components are even absent, e.g. the NH ZM during August 2011 storm. The hemispheric asymmetry during solstices to large extend is caused by the prevailing summer to winter transequatorial thermospheric winds. By using a three-dimensional nonhydrostatic general circulation model driven by measured storm-time input data Yiğit et al. [2016] investigated the response of the thermosphere-ionosphere system to the 5-6 August 2011 geomagnetic storm. They found that besides the thermospheric circulation the thermal response of the SH winter has been overall two times larger than that of the $\mathrm{NH}$ summer, i.e. the neutral temperature increase in the $\mathrm{SH}$ is larger than that in the $\mathrm{NH}$ and additionally enhances the hemispheric asymmetric response.

Figure 9 displays the latitude-UT cross-sections of the amplitudes of nonmigrating D0 (left column of plots) and SPW1 (right column of plots) wave components calculated from the CODE rTEC for the considered disturbed periods. The results for both components are again similar to those for the October 2003 storms. However, because of the strong hemispheric asymmetry for solstice storms some of the components at one of the hemispheres are absent, e.g. the NH D0 and SPW1 components during the storm in August 2011. The nonmigrating D0 tidal wave shows 3 (three) latitude ranges for enhancement: $\pm 40^{\circ}, \pm 60^{\circ}$ and $\pm 80^{\circ}$, while those of SPW1 only around $\pm 40^{\circ}$ and $\pm 60^{\circ}$. These components are geomagnetically forced because their amplitudes are enhanced during the main phases of the storms (please, see the $D_{s t}$-idex plots in the upper row of Figure 7).

The negative anomalies of the considered in this part three geomagnetic storms are formed by the same dominant components as the positive ones as follows: (i) ZM describes this part of the negative anomalies that does not depend on the longitude and LT, and (ii) DW1 and D0 are responsible for the time-dependent part while SPW1 describes longitude dependent part.

\section{Summary}

In the present study, we have examined the structure and variability of the ionospheric TEC anomalies driven by geomagnetic storms. For this purpose the CODE global ionospheric TEC data during four geomagnetically-disturbed periods of time have been considered. By applying the traditional atmospheric tidal analysis to the geomagnetically forced TEC anomalies we have made an attempt to identify the tidal/SPW signatures that may contribute to the generation of these anomalies. First the disturbed period 29 October-01 November 2003 has been studied in detail. The main results from this period have been later fully supported by analogous investigations of the other three disturbed periods.

By using rTEC for describing the TEC anomalies all regular temporal (diurnal, seasonal, etc.) changes are removed from the TEC variability. The longitudinal variations in the ionosphere are primarily imposed by a realistic magnetic field configuration that introduces a special background zonal wave structure of the plasma distribution; the latter however is removed by using rTEC. Therefore the enhanced tidal/SPW components obtained from the applied to the rTEC data tidal analysis are entirely driven by the geomagnetic storms. The repeatable latitude-UT structures of some wave components and their significant amplifications during the main phases of the storms present strong evidence for their origin. The phase structure provides additional evidence for this origin.

It has been already mentioned in the Introduction that the positive ionospheric storms are due to combined effects of disturbed thermospheric wind and electric fields [Tanaka, 1979, 1981, Reddy et al., 1990; Werner et al., 1999; Kelley et al., 2004; Balan et al., 2010]. The geomagnetically forced 
TEC anomalies, shown in Figure 1b, presented in the best way the repeatable spatial distribution of the positive anomalies related to the main phases of the 29-30 October 2004 storms. It has been found that they are composed by 3 (three) types of anomalies with different origin and appearance at different latitudes. These are: (i) Anomalies located near latitudes of $\pm 40^{\circ}$ and related to the enhancement and poleward moving of the EIA which are well seen during the day and early evening hours; they are caused by the combined action of the PPEF having eastward polarity during the day-time and additionally amplified by the divergent horizontal equatorward wind [Kelley et al., 2004; Mannuchi et al., 2005; Balan et al., 2010; 2011]. (ii) Anomalies located near latitudes of $\pm 60^{\circ}$ and seen predominantly in the night-side ionosphere; they are generated by the equatorward expansion of the convection electric fields which push plasma to high altitudes where the recombination is much slower and hence accumulates the plasma [Foster, 1993; Foster et al., 2002; Foster and Rideout, 2007; Heelis et al., 2009], and (iii) Very high latitude anomalies related to the auroral heating and thermospheric expansion leading to a decrease of the top vertical gradient of the electron density profile (plasma scale height increase); this is due to the prevailing role of the dynamics and diffusion processes in shaping the top side F-region [Tulasi Ram et al., 2010a, 2010b; Mukhtarov and Pancheva, 2012].

The decomposition analysis applied to the rTEC revealed that the above mentioned three types of geomagnetically driven anomalies can be reconstructed by superposition of the following dominant components:

- DW1, ZM and SPW1components have dominant contribution to the midlatitude anomalies (near $\pm 40^{\circ}$ ); D0 and other zonally symmetric tidal components have also some contribution.

- The enhanced ZM, D0, DW1 and SPW1 usually shape the high-latitude anomalies (near $\pm 60^{\circ}$ ) seen predominantly in the night-side ionosphere.

- Very high latitude anomalies (near $\pm 80^{\circ}$ ) are formed mainly by ZM and D0 components; the other zonally symmetric tidal components have also some contribution.

The dominant contribution of the above mentioned wave components have been supported also by RMS analysis (Figure 3 and in the bottom row of plots in Figure 7).

Nevertheless that the negative anomalies are not well latitudinally defined they are shaped by the same dominant components as the respective positive ones. We clarify that ZM describes this part of the negative anomalies that does not depend on the longitude and LT, while tidal components and SPW1 are responsible for their time- and longitude-dependent parts respectively.

It is worth mentioning also the peculiar feature of the SPW1 phase at middle latitudes (Figure 6b, left plot); it gradually moves westward making almost a full longitude cycle for 4 days. Such behavior is evident for other storms also but for some of them a complete cycle is done for about 2 days. For all investigated storms here the midlatitude SPW1 phases move westward. When the phase of a given SPW moves westward and makes a full cycle for some days it means that there is westward travelling wave (it is a SPW1 but only in the frame of 24-h window used for the decomposition). This result indicates that during the geomagnetic storms zonally travelling planetary waves are forced in situ. Usually a single storm generates quasi-2-day waves while two successive storms may generate about 4-day planetary waves. It is known that the quasi-2-day activity in the ionosphere increases during geomagnetic storms [Apostolov et al., 1995; Altadill et al., 1997]. Such 2-day waves are in situ forced and a possible generation mechanism related to geomagnetic storms has been suggested by Pancheva et al. [2002]. However, the quasi-2-day oscillations observed in the ionosphere during summer are generated mainly by quasi-2-day waves in the neutral wind of the mesosphere lower-thermosphere region [Pancheva and Lysenko, 1988; Forbes et al., 1997].

Summarizing we note that this study provides a new insight into the ionospheric anomalies driven by geomagnetic storms. The paper clarifies how the geomagnetic storms significantly distort the normal diurnal behavior and background zonal structure of the ionosphere. 
Acknowledgement: We are grateful to the CODE TEC team for the access to the TEC data provided from the CODE FTP directory: ftp://ftp.unibe.ch/aiub/CODE/, to the WDC, Boulder, USA for the access to geomagnetic on: http://spidr.ngdc.noaa.gov/spidr/index.jsp and for the access to the Hemispheric Power Index on: http://www.swpc.noaa.gov/. This work was supported by the European Office of Aerospace Research and Development (EOARD), Air Force Office of Scientific Research, Air Force Material Command, USAF, under grant number FA8655-12-1-2057 to D. Pancheva.

\section{REFERENCES}

Abdu, M. A., de Souza, J. R., Sobral, J. H. A., Batista, I. S., 2006. Magnetic storm associates disturbance dynamo effects over low and equatorial latitude ionosphere, in Recurrent Magnetic Storms: Corotating Solar Wind Streams, Geophys. Monogr. Ser., v. 167, B. Tsurutani et al. (Ed), pp. 283-304, AGU, Washington, D. C.

Altadill, D., Apostolov, E. M., Alberca, L. F., 1997. Some seasonal hemispheric similarities in foF2 quasi-2-day oscillations. J. Geophys. Res. 102, 9737-9739.

Apostolov, E. M., Altadill, D., Alberca, L. F., 1995. Characteristics of quasi-2-day oscillations in the $f_{o} \mathrm{~F} 2$ at northern middle latitudes. J. Geophys. Res. 100, 12 163-12 171.

Balan, N., Shiokawa, K., Otsuka, Y., Watanabe, S., Bailey, G. J., 2009. Super plasma fountain and equatorial ionization anomaly during penetration electric field. J. Geophys. Res. 114, A03310, doi:10.1029/2008JA013768.

Balan, N., Shiokawa, K., Otsuka, Y., Kikuchi, T., Vijaya Lekshmi, D., Kawamura, S., Yamamoto, M., Bailey, G. J. 2010. A physical mechanism of positive ionospheric storms at low latitudes and midlatitudes. J. Geophys. Res. 115, A02304, doi:10.1029/2009JA014515.

Balan, N., Yamamoto, M., Liu, J. Y., Otsuka, Y., Liu, H., Lühr, H., 2011. New aspects of thermospheric and ionospheric storms revealed by CHAMP. J. Geophys. Res. 116, A07305, doi:10.1029/2010JA016399.

Batista, I. S., de Paula, E., Abdu, M. A., Trivedi, N., Greenspan, M., 1991. Ionospheric effects of the March 13, 1989, magnetic storm at low and equatorial latitudes. J. Geophys. Res. 96(A8), $13,943-13,952$.

Blanc, M., Richmond, A. D., 1980. The ionospheric disturbance dynamo. J. Geophys. Res. 85(A4), $1669-1699$.

Buonsanto, M. J., 1999. Ionospheric storms - A review. Space Sci. Rev. 88, 563-601.

Chang, L.C., Liu, H., Miyoshi, Y., Chen, C.-H., Chang, F.-Y., Lin, C.-H., Sun, Y.-Y., 2015. Structure and origins of the Weddell Sea Anomaly from tidal and planetary wave signatures in FORMOSAT-3/COSMIC observations and GAIA GCM simulations. J. Geophys. Res. 120, 1325-1340, doi:10.1029/2014JA020752.

Fejer, B. G., Scherliess, L., 1998. Mid- and low-latitude prompt penetration ionospheric plasma drifts. Geophys. Res. Lett. 25(16), 3071-3074. 
Fejer, B. G., Jensen, J.W., Kikuchi, T., Abdu, M.A., Chau, J.L., 2007. Equatorial ionospheric electric fields during the November 2004 magnetic storm. J. Geophys. Res. 112, A10304, doi:10.1029/2007JA012376.

Field, P. R., Rishbeth, H., 1997. The response of the ionospheric F2-layer to geomagnetic activity: An analysis of worldwide data. J. Atmos. Sol-Terr. Phys. 59, 163-180.

Forbes, J. M., Guffee, R., Zhang, X., Fritts, D., Riggin, D., Manson, A., Meek, C., Vincent, R. A., 1997. Quasi-2-day oscillation of the ionosphere during summer 1992. J. Geophys. Res. 102, 7301-7305.

Foster, J. C., 1993. Storm-time plasma transport at middle and high latitudes. J. Geophys. Res. 98, $1675-1689$.

Foster, J. C., Erickson, P. J., Coster, A. J., Goldstein, J., Rich, F. J., 2002. Ionospheric signatures of plasmaspheric tails. Geophys. Res. Lett. 29(13), 1623, doi:10.1029/2002GL015067.

Foster, J. C., Rideout, W., 2007. Storm enhanced density: Magnetic conjugacy effects. Ann. Geophys. 25, 1791-1799.

Fuller-Rowell, T. J., Codrescu, M.V., Rishbeth, H., Moffett, R.J., Quegan, S., 1994. Response of the thermosphere and ionosphere to geomagnetic storms. J. Geophys. Res. 99, 3893-3914.

Fuller-Rowell, T. J., Codrescu, M.V., Rishbeth, H., Moffett, R.J., Quegan, S., 1996. On the seasonal response of the thermosphere and ionosphere to geomagnetic storms. J. Geophys. Res. 101, 2343-2353.

Fuller-Rowell, T.J., Codrescu, M.V., Wilkinson, M., 2000. Quantitative modelling of the ionospheric response to geomagnetic activity. Ann. Geophys. 18, 766-781.

Heelis, R. A., Sojka, J. J., David, M., Schunk, R. W., 2009. Storm time density enhancements in the mid latitude dayside ionosphere. J. Geophys. Res. 114, A03315, doi:10.1029/ 2008JA013690.

Hernández-Pajares, M., Juan, J. M., Sanz, J., Orus, R., Garcia-Rigo, A., Feltens, J., Komjathy, A., Schaer, S. C., Krankowski, A., 2009. The IGS VTEC maps: A reliable source of ionospheric information since 1998. J. Geod. 83, 263-275, doi:10.1007/s00190-008-0266-1.

Jakowski, N., Wilken, V., Schlueter, S., et al., 2005., Ionospheric space weather effects monitored by simultaneous ground and spaced based GNSS signals. J. Atmos. Sol.-Terr. Phys. 67(12), 1074-1084, doi:10.1016/j.jastp.2005.02.023.

Jones M., Forbes, J.M., Hagan, M.E., Maute, A., 2013. Non-migrating tides in the ionospherethermosphere: In situ versus tropospheric sources. J. Geophys. Res. 118, 2438-2451, doi:10.1029/jgra.50257.

Kelley, M. C., Fejer, B. G., Gonzales, C. A., 1979. An explanation for anomalous ionospheric electric fields associated with a northward turning of the interplanetary magnetic field. Geophys. Res. Lett. 6(4), 301-304.

Kelley, M. C., Vlasov, M. N., Foster, J. C., Coster, A. J., 2004. A quantitative explanation for the phenomenon known as storm-enhanced density. Geophys. Res. Lett. 31, L19809, doi:10.1029/2004GL020875.

Kikuchi, T., Lühr, H., Kitamura, T., Saka, O., Schlegel, K., 1996. Direct penetration of the polar electric field to the equator during DP2 event as detected by the auroral and equatorial magnetometer chains and the EISCAT radar. J. Geophys. Res. 101(A8), 17161- 17174.

Kutiev, I., Muhtarov, P., 2001. Modeling of midlatitude F-region response to geomagnetic activity, J. Geophys. Res. 106(A8), 15501-15510.

Kutiev, I., Muhtarov, P., 2003. Empirical modeling of global ionospheric foF2 response to geomagnetic activity. J. Geophys. Res. 108(A1), 1021, doi:10.1029/2001JA009134. 
Lin, C. H., Richmond, A. D., Heelis, R. A., Bailey, G. J., Lu, G., Liu, J. Y., Yeh, H. C., Su, S. Y., 2005. Theoretical study of the low- and mid-latitude ionospheric electron density enhancement during the October 2003 storm: Relative importance of the neutral wind and the electric field. J. Geophys. Res. 110, A12312, doi:10.1029/2005JA011304.

Lu, G., Goncharenko, L. P., Richmond, A. D., Roble, R. G., Aponte, N., 2008. A dayside ionospheric positive storm phase driven by neutral winds. J. Geophys. Res. 113, A08304, doi:10.1029/2007JA012895.

Mannucci, A. J., Tsurutani, B. T., Ijima, B. A., Komjathy, A., Saito, A., Gonzalez, W. D., Guarnieri, F. L., Kozyra, U. J., Skoug, R., 2005. Dayside global ionospheric response to the major interplanetary events of October 29 - 30, 2003 “Halloween Storm”. Geophys. Res. Lett. 32, L12S02, doi:10.1029/2004GL021467.

Mendillo, M., Papagiannis, M. D., Klobuchar, J. A., 1970. Ionospheric storms at midlatitudes. Radio Sci. 5, 895-898.

Mendillo, M., Klobuchar, J., 1975. Investigations of the ionospheric F region using multistation total electron content observations. J. Geophys. Res. 80, 643-650.

Mendillo, M., He, X.-Q., Rishbeth, H., 1992. How the effects of winds and electric fields in F2layer storms vary with latitude and longitude: A theoretical study. Planet. Space Sci. 40, 595606.

Mendillo, M., 2006. Storms in the ionosphere: Patterns and processes for total electron content. Rev. Geophys. 44, RG4001, doi:10.1029/2005RG000193.

Muhtarov, P. Kutiev, I., 1998. Empirical modeling of ionospheric storms at midlatitudes. Adv. Space Res. 22(6), 829- 835.

Mukhtarov, P., Pancheva, D., Andonov, B., 2010. Climatology of the stationary planetary waves seen in the SABER/TIMED temperatures (2002-2007). J. Geophys. Res. 115, A06315, doi:10.1029/2009JA015156.

Mukhtarov, P., Pancheva, D., 2012. Thermosphere-ionosphere coupling in response to recurrent geomagnetic activity. J. Atmos. Sol-Terr. Phys. 90-91, 132-145, doi:10.1016/ j.jastp.2012.02.013.

Mukhtarov, P., Pancheva, D., Andonov, B., Pashova, L., 2013a. Global TEC maps based on GNSS data: 1. Empirical background TEC model. J. Geophys. Res. 118, 4594-4608, doi:10.1002/jgra.50413.

Mukhtarov, P., Andonov, B., Pancheva, D., 2013b. Global empirical model of TEC response to geomagnetic activity. J. Geophys. Res. 118, 6666-6685, doi:10.1002/jgra.50576.

Pancheva, D. Lysenko, I., 1988. Quasi-two-day fluctuations observed in the summer F-region electron maximum. Bulg. Geophys. J. 14(2), 41-51.

Pancheva D., Mitchell, N., Clark, R.R., Drobjeva, J., Lastovicka. J., 2002. Variability in the maximum height of the ionospheric F2-layer over Millstone Hill (September 1998 - March 2000); influence from below and above. Ann. Geophys. 20, 1807-1819.

Pancheva D., Mukhtarov, P., Andonov, B., Mitchell, N.J., Forbes, J., 2009. Planetary waves observed by TIMED/SABER in coupling the stratosphere-mesosphere-lower thermosphere during the winter of 2003/2004: Part 1, Comparison with the planetary waves observed in the UKMO temperature data. J. Atmos. Sol.-Terr. Phys. 71(1), 61-74.

Pancheva, D., Mukhtarov, P., 2010. Strong evidence for the tidal control on the longitudinal structure of the ionospheric F-region. Geophys. Res. Lett., 37, L14105, doi:10.1029/ 2010 GL044039. 
Pancheva, D., Mukhtarov, P., 2012. Global response of the ionosphere to atmospheric tides forced from below: Recent progress based on satellite measurements. Space Sci. Rev. 161, 1-35, doi:10.1007/s11214-011-9837-1.

Prölss, G.W., 1980. Magnetic storm associated perturbations of the upper atmosphere: Recent results obtained with satellite-borne gas analyzers. Rev. Geophys. Space Phys. 18, 183-202.

Prölss, G.W., 1991. Thermosphere-ionosphere coupling during disturbed conditions. J. Geomag. Geoelectr. 43 (suppl.), 537-549.

Prölss, G.W., 1993. On explaining the local time variations of ionospheric storm effects. Ann. Geophys. 11, 1-9.

Prölss, G.W., 1995. Ionospheric F-region storms. In: Volland H. (Ed.), Handbook for Atmospheric Electrodynamics, vol. 2, CRC Press, Boca Raton, pp. 195-248.

Prölss G.W., 2008. Ionospheric storms at mid-latitudes: a short review. In: Kintner P.M. (Ed.) Midlatitude ionospheric dynamics and disturbances, AGU monograph 181, American Geophysical Union, Washington, pp 9-24.

Prölss G.W., 2011. Density perturbations in the upper atmosphere caused by the dissipation of solar wind energy. Surveys in Geophysics 32, No 2, 101-195.

Reddy, C. A., Fukao, S., Takami, T., Yamamoto, M., Tsuda, T., Nakamura, T., Kato, S., 1990. A MU radar-based study of mid-latitude $\mathrm{F}$ region response to a geomagnetic disturbance. $\mathrm{J}$. Geophys. Res. 95, 21077- 21094.

Richmond, A. D., Peymirat, C., Roble, R. G., 2003. Long-lasting disturbances in the equatorial ionospheric electric field simulated with a coupled magnetosphere-ionosphere-thermosphere model. J. Geophys. Res. 108(A3), 1118, doi:10.1029/2002JA009758.

Rishbeth, H., 1991. F-region storms and thermospheric dynamics. J. Geomag. Geoelectr. 43 (suppl.), 513-524.

Rishbeth, H., 1998. How the thermospheric circulation affects the ionospheric F2-layer. J. Atmos. Terr. Phys. 60, 1385-1402.

Schaer, S., 1999. Mapping and Predicting the Earth's Ionosphere Using the Global Positioning System, Geod. Geophys. Arb. Schweiz., vol. 59, Inst. für Geod. und Photogramm., Zurich, Switzerland.

Stankov, S.M., Stegen, K., Warnant, R., 2010. Seasonal variations of storm-time TEC at European middle latitudes. Adv. Space Res. 46(10), 1318-1325.

Tanaka, T., 1979. The worldwide distribution of positive ionospheric storms. J. Atmos. Terr. Phys. 41, 103-110.

Tanaka, T. 1981. Severe ionospheric disturbances caused by the sudden response of evening subequatorial ionospheres to geomagnetic storms. J. Geophys. Res. 86, 11335-11349.

Trichtchenko, L., Zhukov, A., Van Der Linden, R., et al., 2007. November 2004 space weather events - real time observations and forecasts. Space Weather 5(6), S06001, doi:10.1029/2006SW000281.

Tulasi Ram, S., Lei, J., Su, S.-Y., Liu, C.H., Lin, C.H., Chen, W.S., 2010a. Dayside ionospheric response to recurrent geomagnetic activity during the extreme solar minimum of 2008. Geophys. Res. Lett. 37, L02101, doi:10.1029/2009GL041038.

Tulasi Ram, S., Liu, C.H., Su, S.-Y., 2010b. Periodic solar wind forcing due to recurrent coronal holes during 1996-2009 and its impact on Earth's geomagnetic and ionospheric properties during the extreme solar minimum. J. Geophys. Res. 115, A12340, doi:10.1029/ 2010JA015800. 
Werner, S., Bauske, R., Prölss G. W., 1999. On the origin of positive ionospheric storms. Adv. Space. Res. 24, 1485-1489.

Yiğit, E., Frey, H.U., Moldwin, M.B., Immel, T.J., Ridley, A.J., 2016. Hemispheric Differences in the Response of the Upper Atmosphere to the August 2011 Geomagnetic Storm: A Simulation Study. J. Atmos. Sol.-Terr. Phys. 141, 13-26, doi:10.1016/j.jastp.2015.10.002.

\section{FIGURE CAPTIONS}

Figure 1 (a) Variations of the equatorial $D_{s t}$-index (in nT, upper left plot), 3-hourly $K_{p}$-index (upper left plot) and Hemispheric Power Index (in gigawatts, bottom plot) for Northern Hemisphere (blue color) and Southern Hemisphere (red color) during 29 October - 01 November 2003; (b) Relative CODE TEC maps in geographic coordinate system for 29 October at 09 UT (upper plot), 30 October at 00 UT (second plot), 30 October at 12 UT (third plot) and 30 October at 23 UT (bottom plot). The modip latitude is marked by white line while the terminator is shown by grey line.

Figure 2 Latitude distribution of CODE rTEC during 29 October - 01 November 2003 at the following fixed longitudes: $180^{\circ} \mathrm{W}$ (upper plot); $90^{\circ} \mathrm{W}$ (second plot); $00^{\circ} \mathrm{E}$ (third plot) and $90^{\circ} \mathrm{E}$ (bottom plot); the white line shows the zero rTEC.

Figure 3 RMS calculated for each decomposition component of the CODE rTEC (according to the text) for the disturbed period of time, 29 October - 01 November 2003. Both RMS of all data and of the full decomposition for the same period of time are shown in the upper part of the figure.

Figure 4 (a) Zonal mean (ZM) of the CODE rTEC; the white line marks zero ZM; (b) Amplitude of the CODE rTEC DW1; (c) Phase (in LT) of the CODE rTEC DW1 at latitudes of $\pm 40^{\circ}$ (left plot) and $\pm 60^{\circ}$ (right plot) for the period of time 29 October - 01 November 2003; the phases for the NH are in blue color while those for the $\mathrm{SH}$ are in red color.

Figure 5 (a) Amplitudes of the nonmigrating D0 (left plot) and S0 (right plot); (b) Phases (in UT) of the D0 (left column of plots) and S0 (right column of plots) tidal components for latitudes of $\pm 60^{\circ}$ (upper row of plots) and $\pm 80^{\circ}$ (bottom row of plots) calculated from the CODE rTEC for the period of time 29 October - 01 November 2003; again the phases for the $\mathrm{NH}$ are in blue color while those for the SH are in red color.

Figure 6 (a) Amplitude of CODE rTEC SPW1; (b) Phase (in degree) of the CODE rTEC SPW1 at latitudes of $\pm 40^{\circ}$ (left plot) and $\pm 60^{\circ}$ (right plot) for the period of time 29 October -01 November 2003.

Figure 7 Variations of the equatorial $D_{s t}$-index (in nT, upper row of plots), 3-hourly $K_{p}$-index (middle row of plots) and RMS calculated for each decomposition component of the CODE rTEC for the following disturbed periods: 07-10 November 2004 (left column of plots), 13-16 December 2006 (middle column of plots) and 04-07 August 2011 (right column of plots).

Figure 8 Latitude-UT cross-sections of ZM (left column of plots) and amplitudes of DW1 (right column of plots) components calculated from the CODE rTEC for the following disturbed periods: 07-10 November 2004 (upper row of plots), 13-16 December 2006 (middle row of plots) and 04-07 August 2011 (bottom row of plots).

Figure 9 Latitude-UT cross-sections of the amplitudes of nonmigrating D0 (left column of plots) and SPW1 (right column of plots) wave components calculated from the CODE rTEC for the following disturbed periods: 07-10 November 2004 (upper row of plots), 13-16 December 2006 (middle row of plots) and 04-07 August 2011 (bottom row of plots). 
(a)
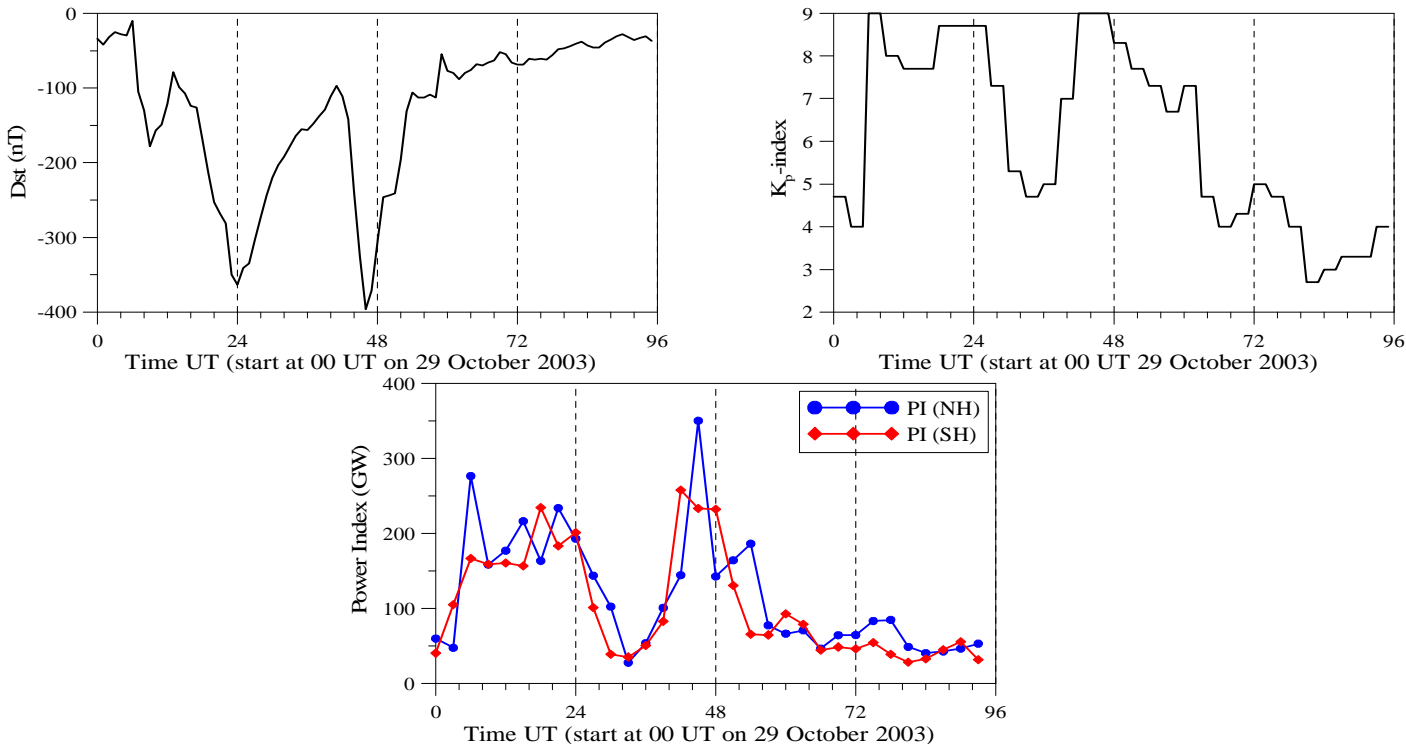

(b)
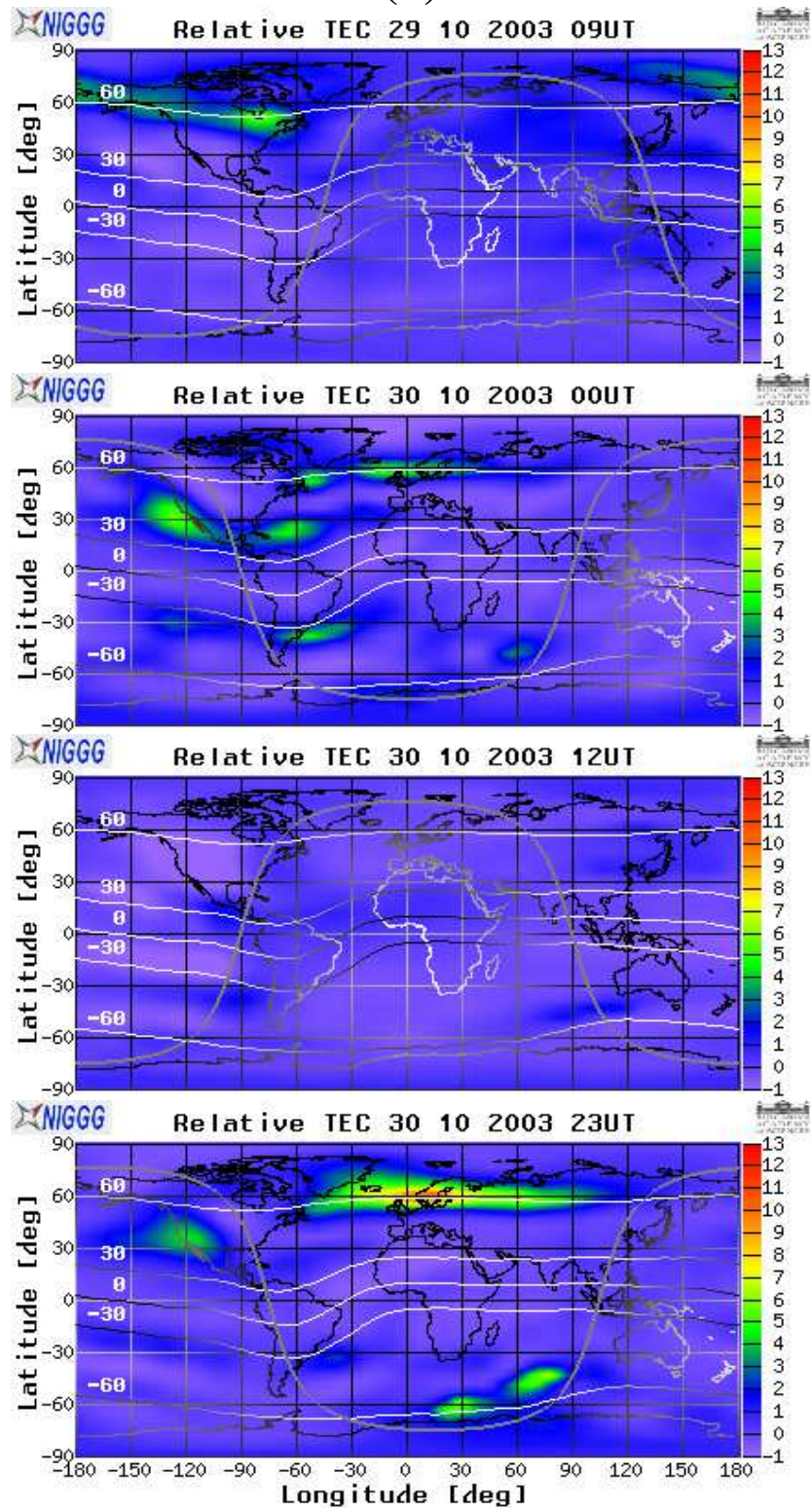

Figure 1 

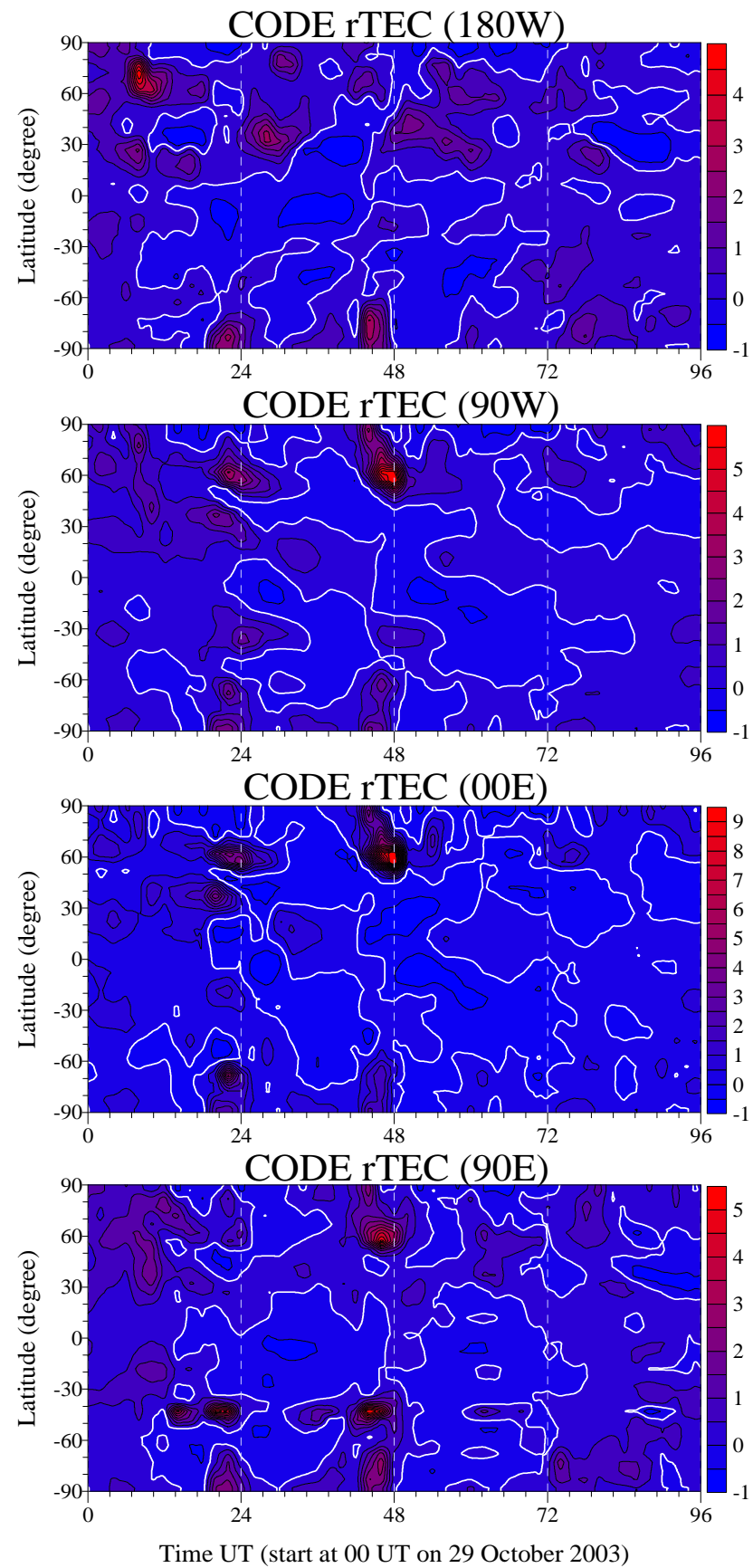

Figure 2 


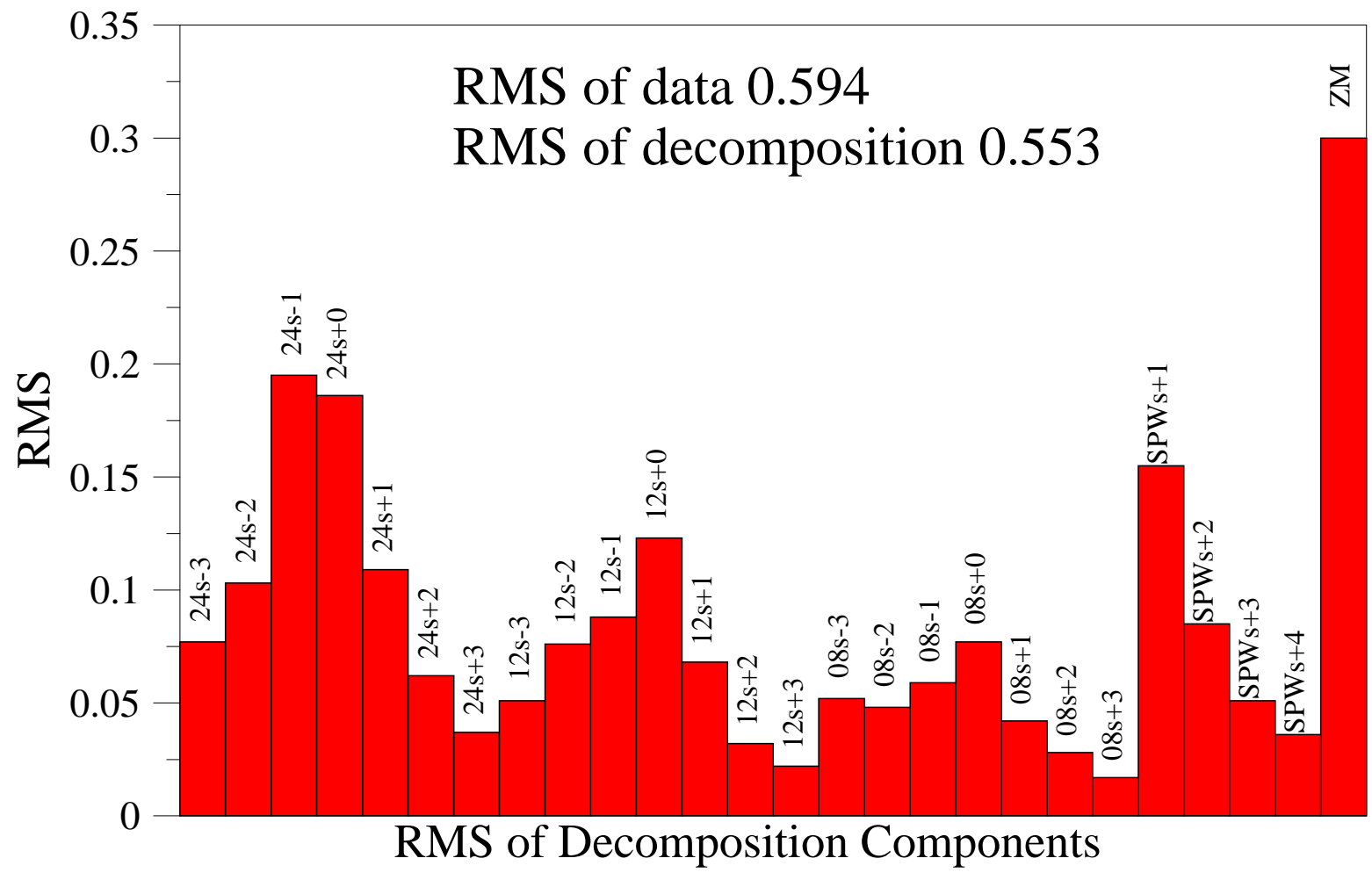

Figure 3 
(a)

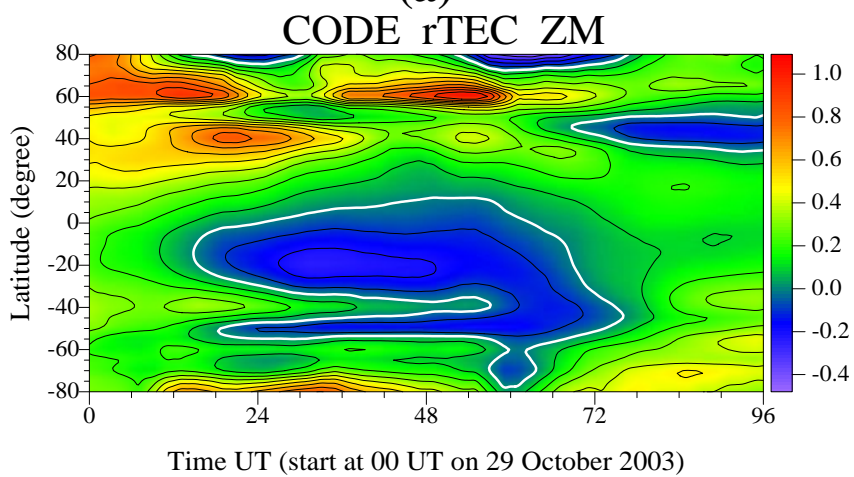

(b)

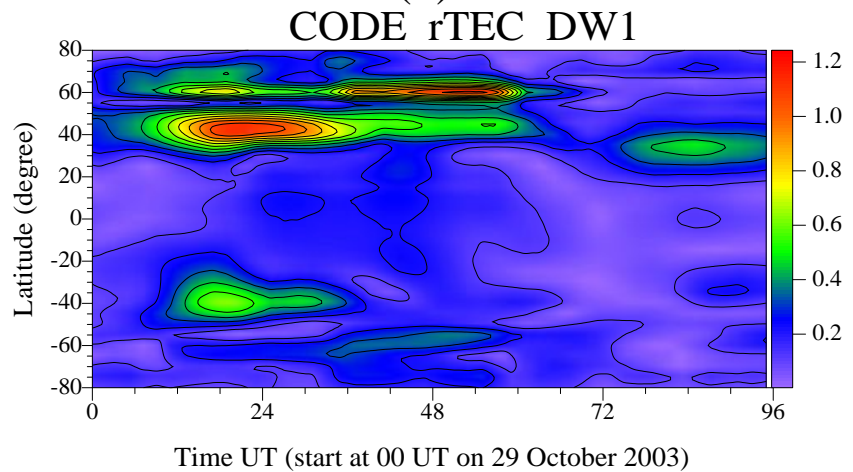

(c)
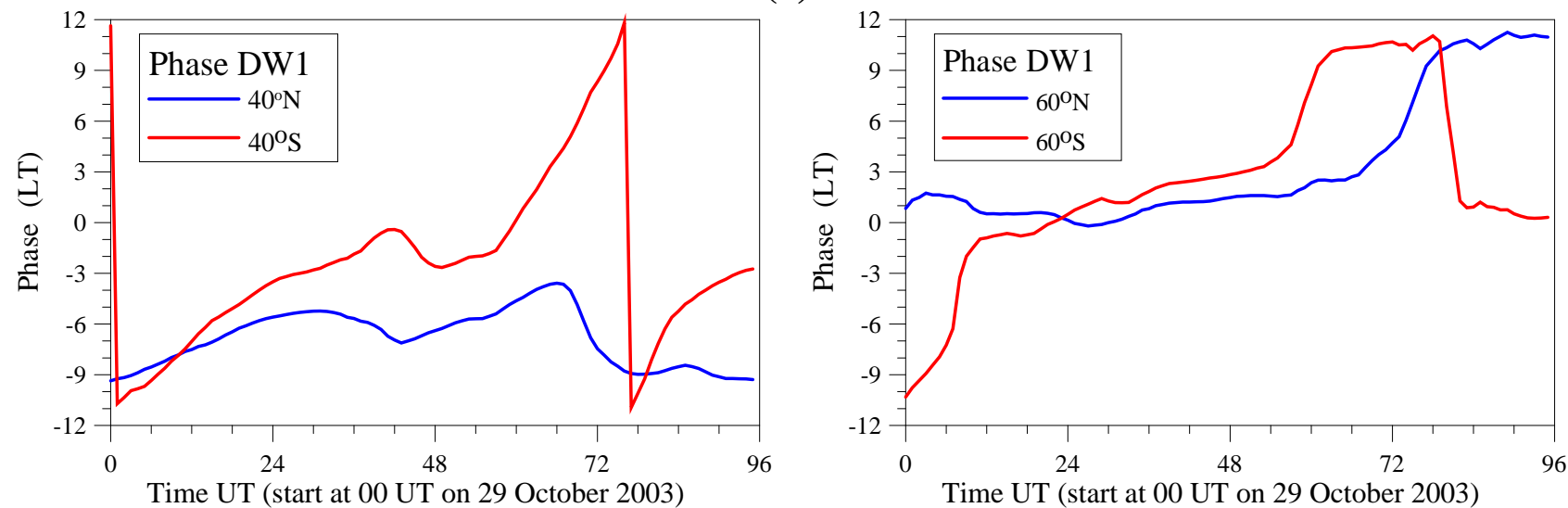

Figure 4 


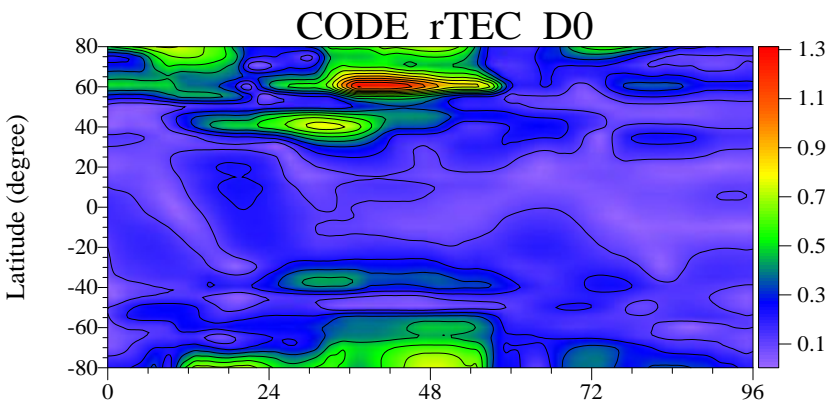

Time UT (start at 00 UT on 29 October 2003)
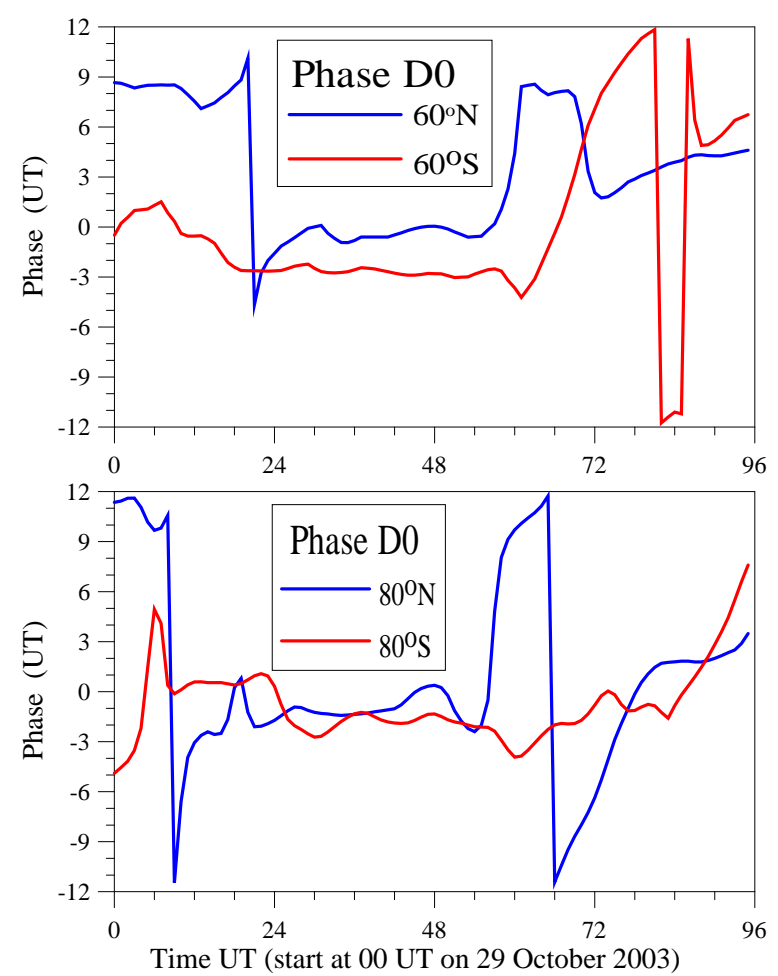

(a)

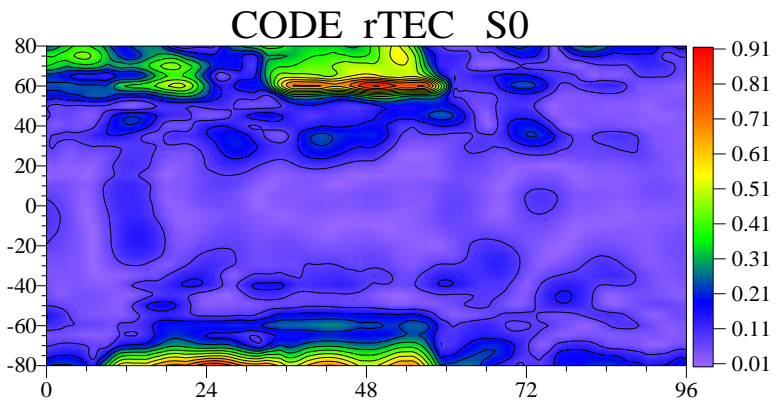

Time UT (start at 00 UT on 29 October 2003)

(b)
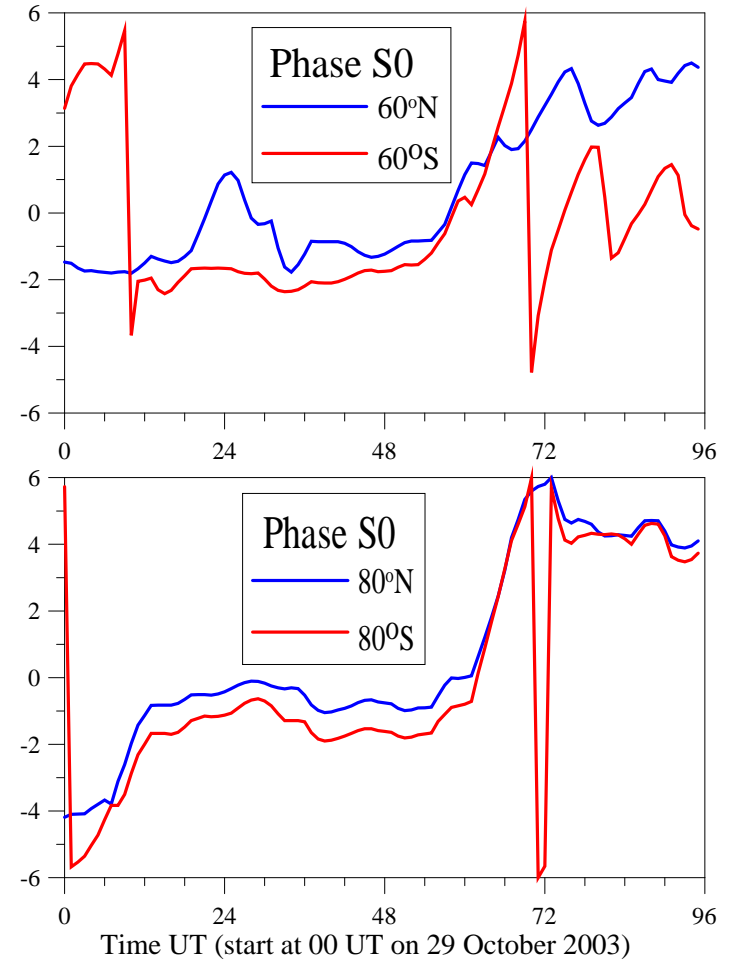

Figure 5 
(a)

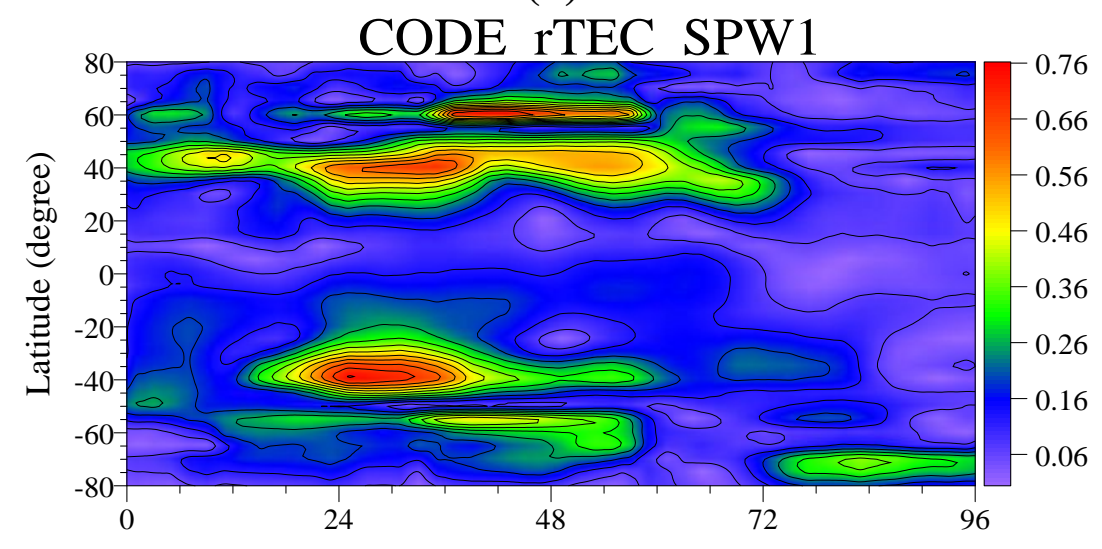

Time UT (start at 00 UT on 29 October 2003)

(b)
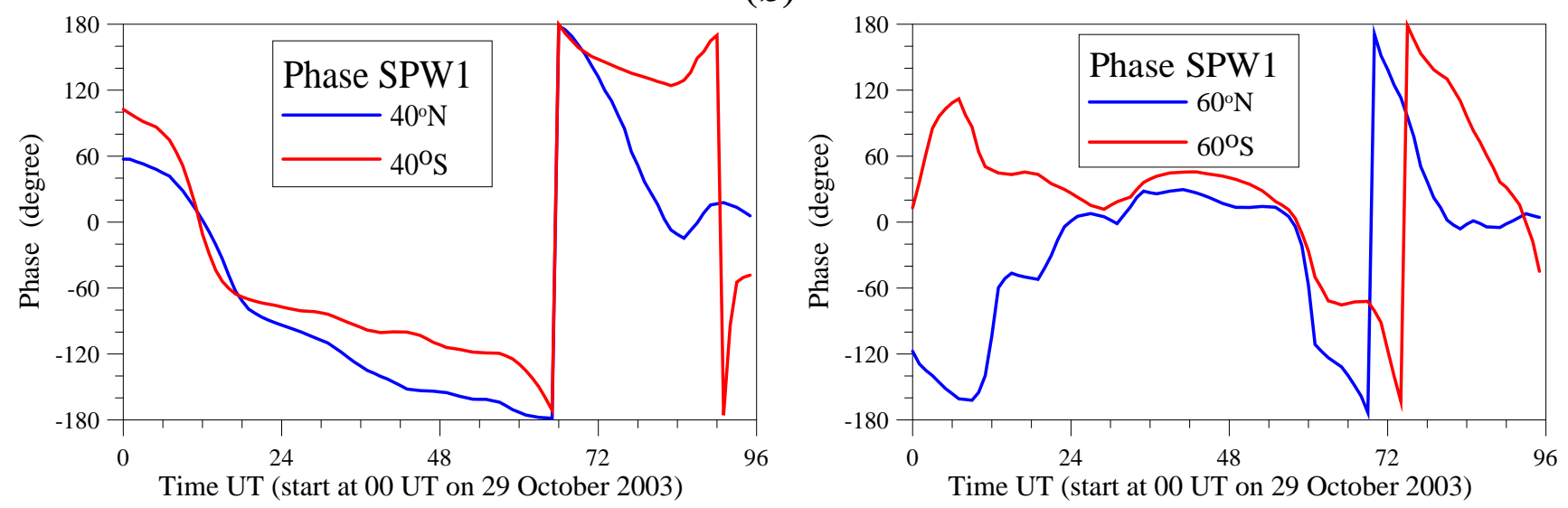

Figure 6 

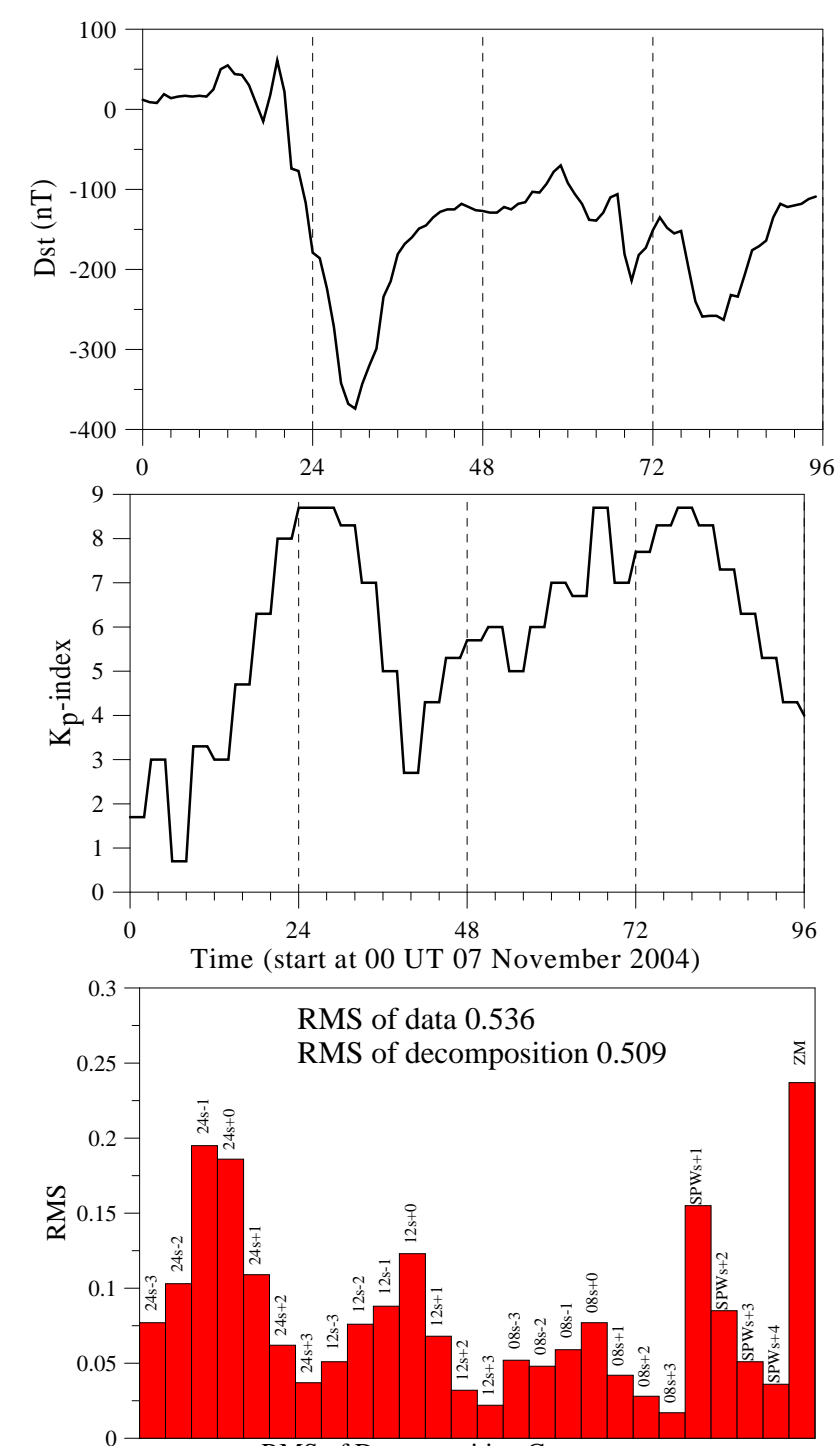

RMS of Decomposition Components
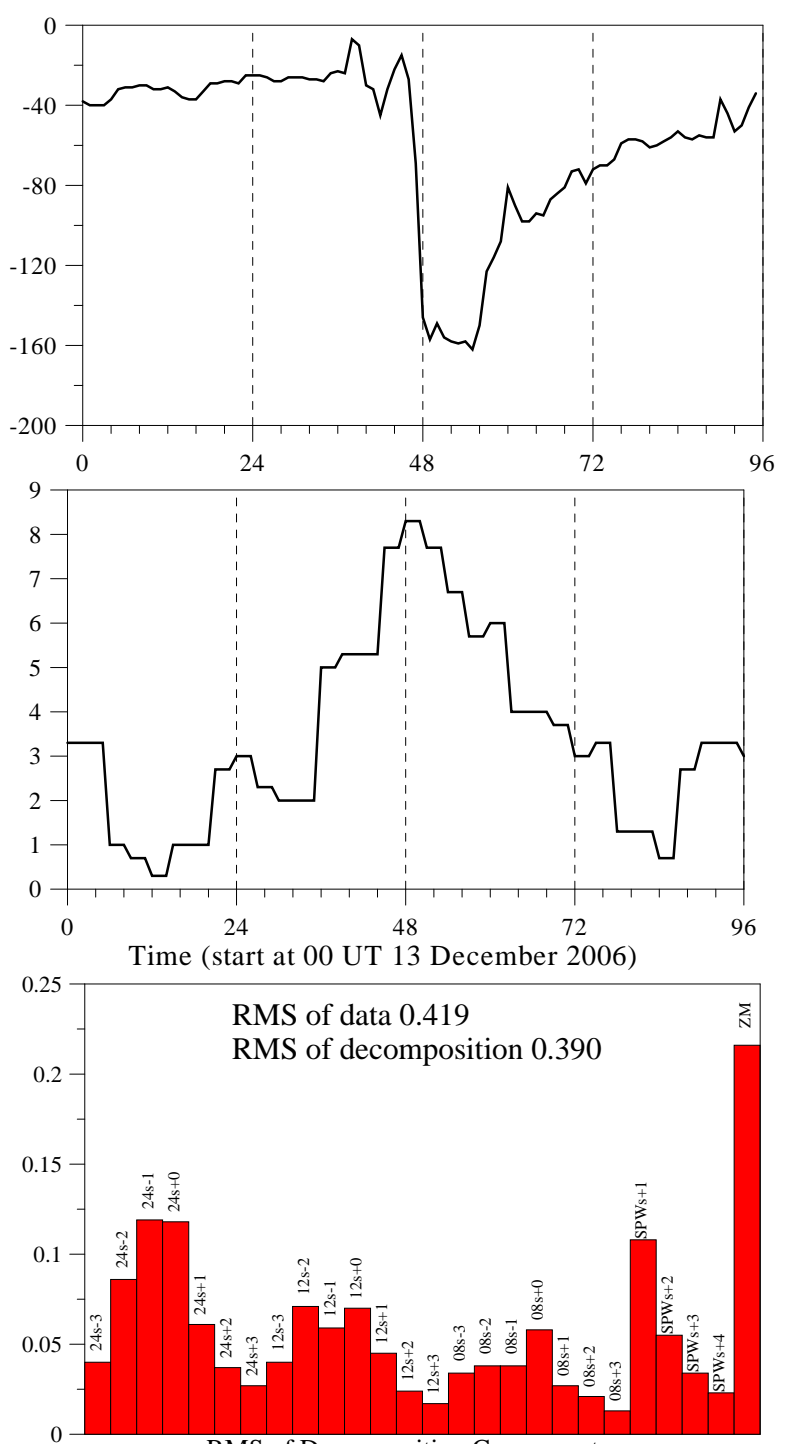

RMS of Decomposition Components

Figure 7
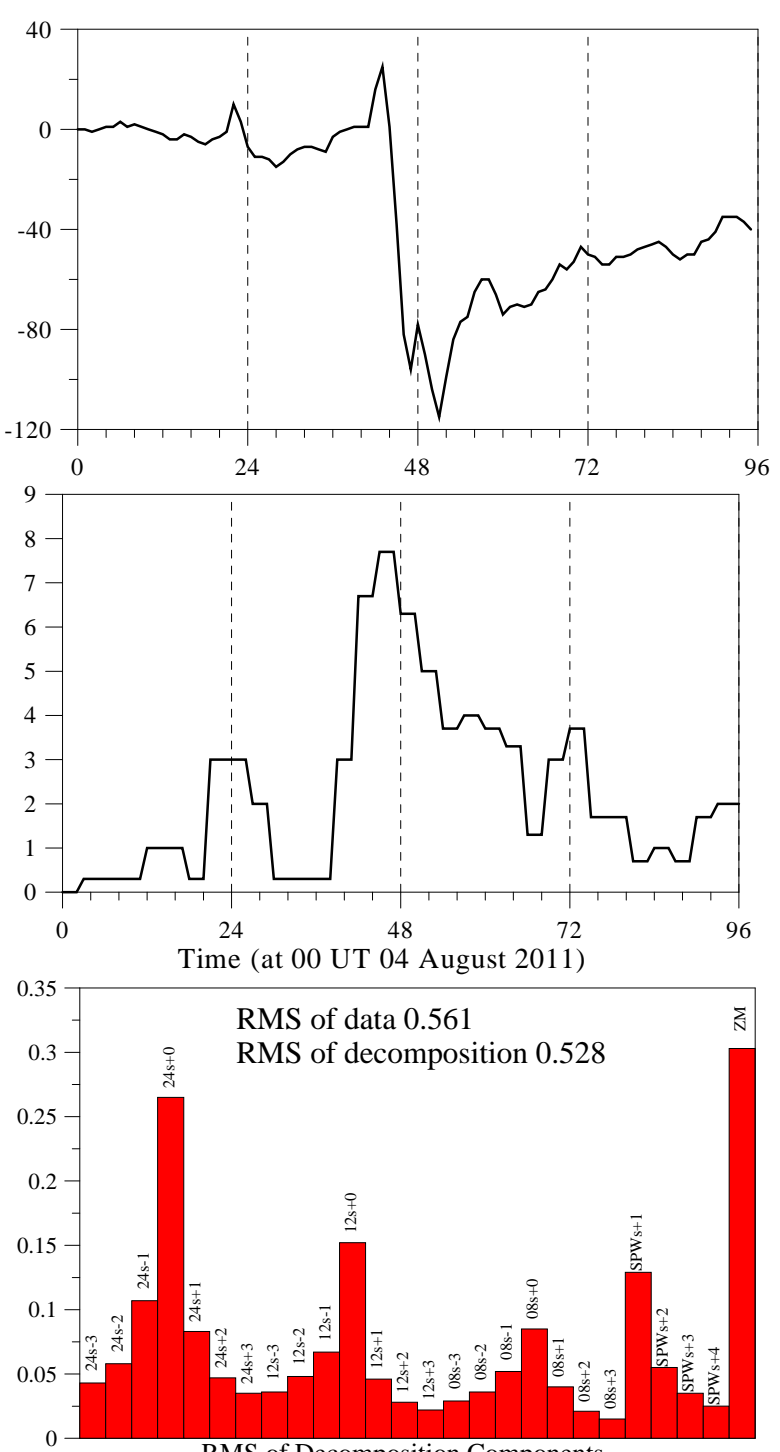

RMS of Decomposition Components 

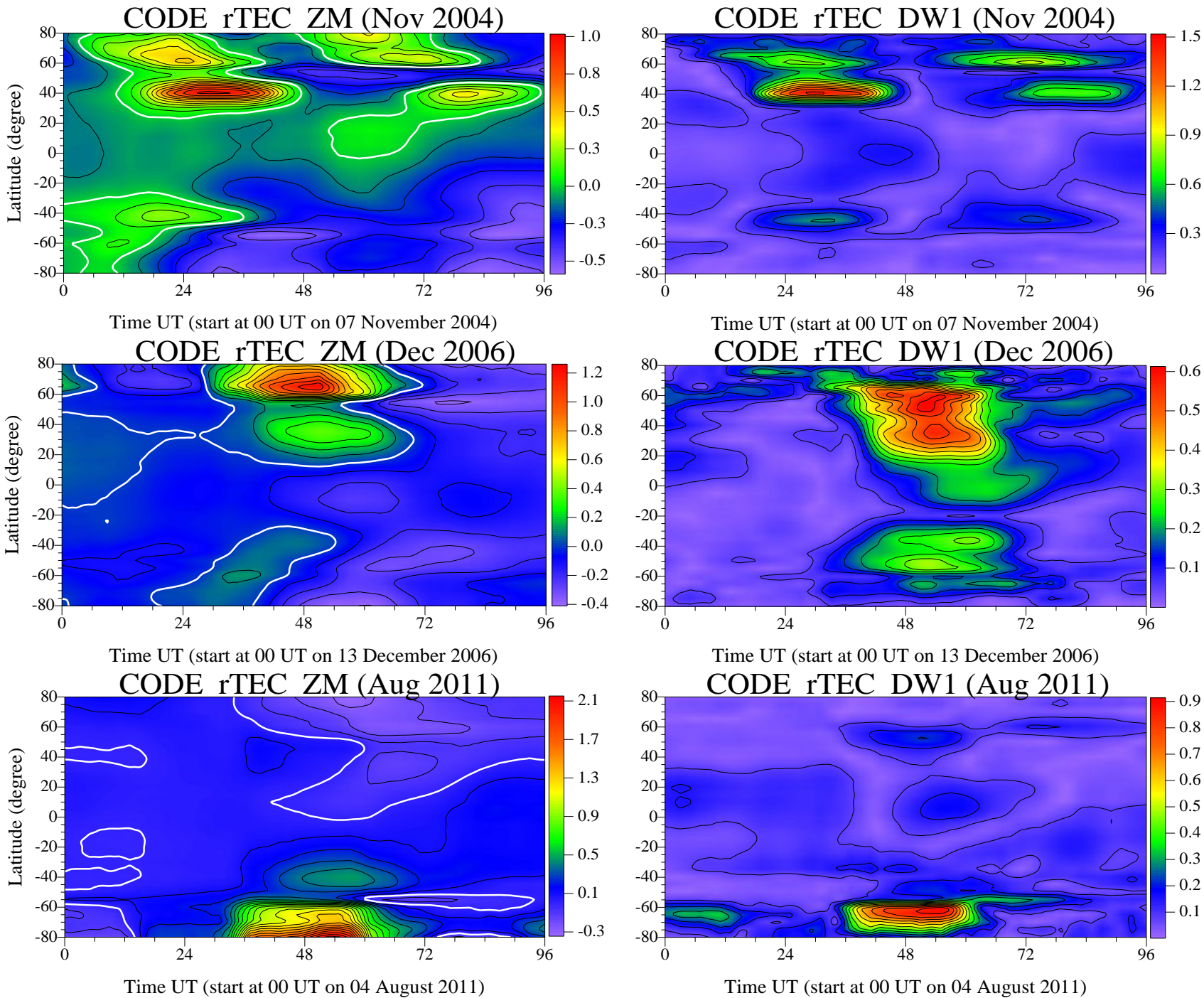

Time UT (start at 00 UT on 04 August 2011)

Figure 8 

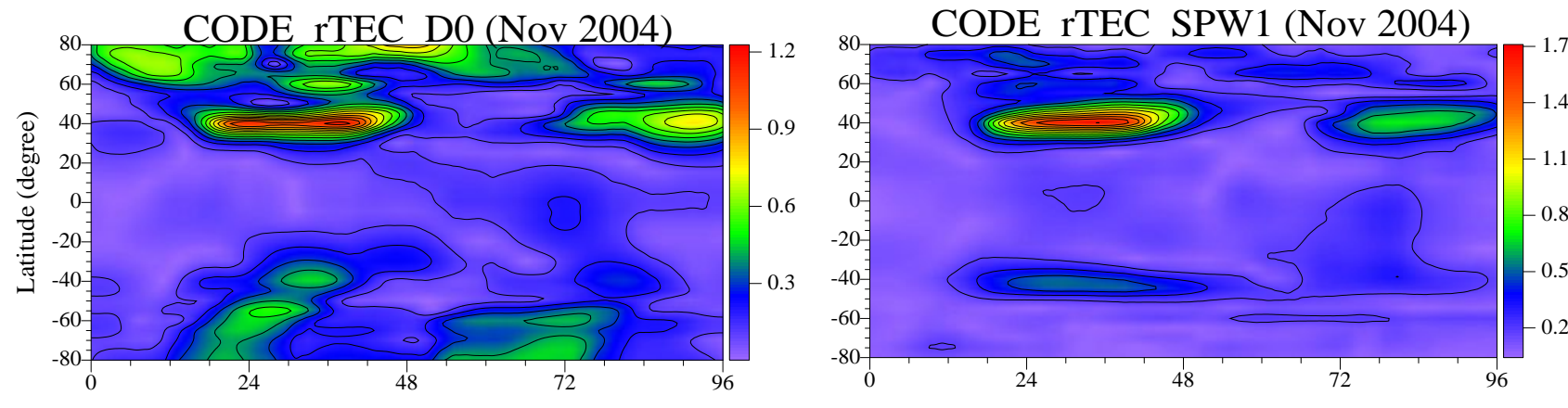

Time UT (start at 00 UT on 07 November 2004)
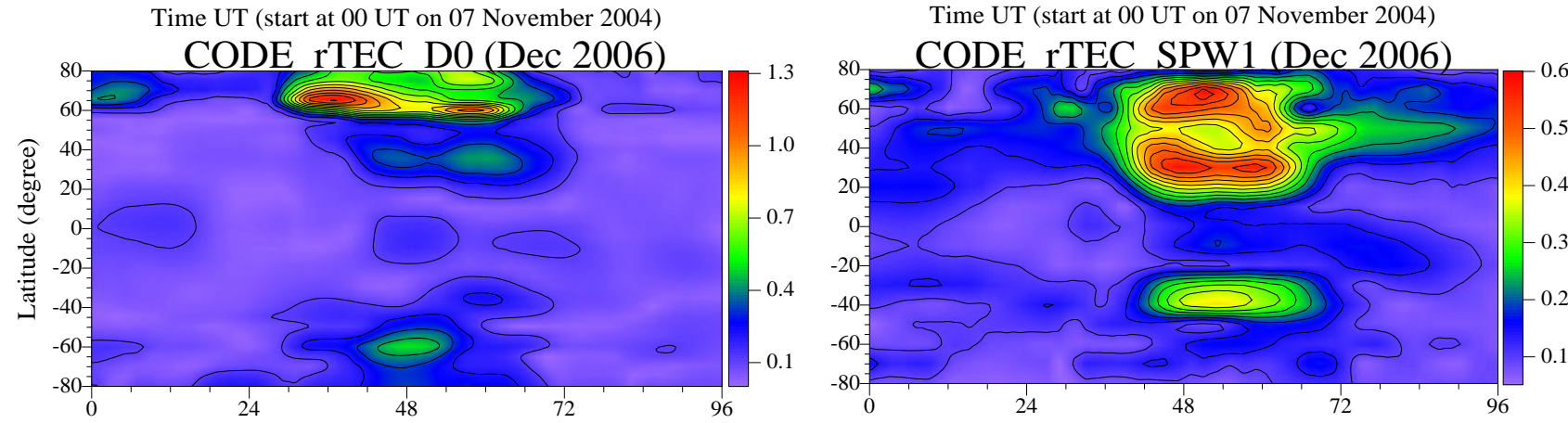

Time UT (start at 00 UT on 13 December 2006)

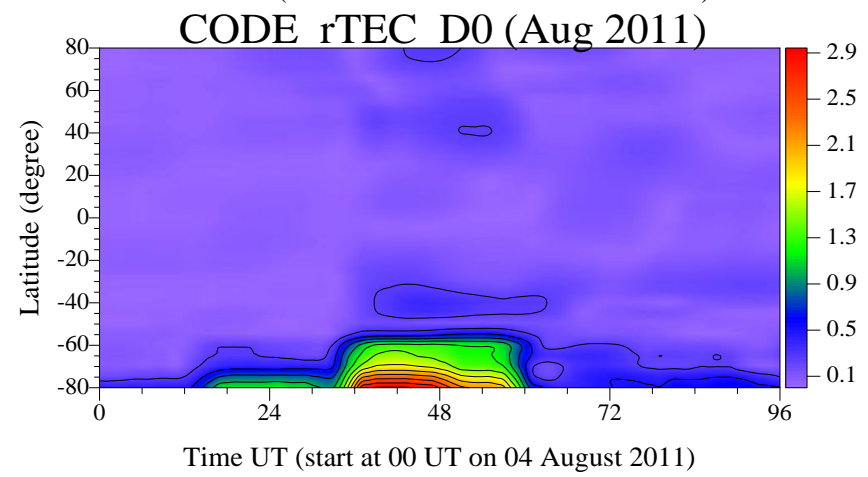

Time UT (start at 00 UT on 13 December 2006)

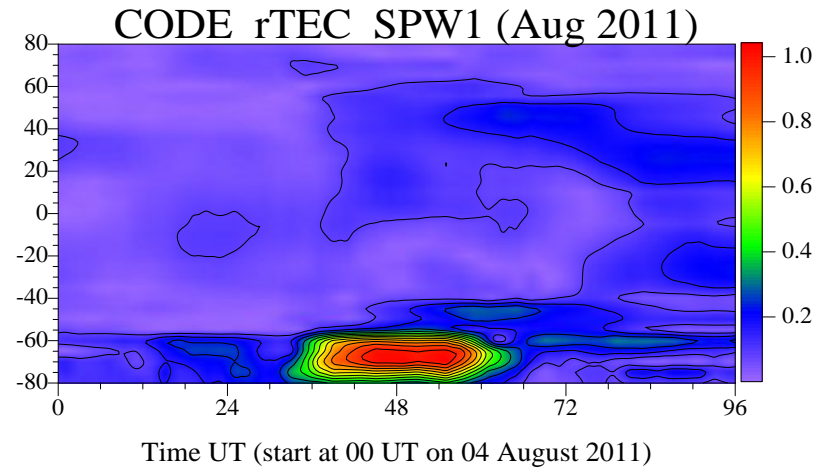

Figure 9 